\title{
Can a Subcapital Osteotomy Fixed with an Intramedullary Locking Plate Correct All Possible Deformities of a Mild to Moderate Hallux Valgus?
}

\author{
Michael Vitek, Hannes Kugler, Felix Fink, Ornella Vitek \\ Center for Foot and Joint Surgery Vienna, Vienna, Austria \\ Email:michael@vitek.wien
}

How to cite this paper: Vitek, M., Kugler, H., Fink, F. and Vitek, O. (2017) Can a Subcapital Osteotomy Fixed with an Intramedullary Locking Plate Correct All Possible Deformities of a Mild to Moderate Hallux Valgus?. Open Journal of Orthopedics, 7, 254-283.

https://doi.org/10.4236/ojo.2017.79027

Received: July 6, 2017

Accepted: September 1, 2017

Published: September 4, 2017

Copyright $\odot 2017$ by authors and Scientific Research Publishing Inc. This work is licensed under the Creative Commons Attribution International License (CC BY 4.0).

http://creativecommons.org/licenses/by/4.0/

\section{(c) (i) Open Access}

\begin{abstract}
Background: There are at least 5 very popular methods described for the correction of mild to moderate hallux valgus deformities. Despite of reported and self experienced good results in favorable fitting preoperative anatomical conditions of some of these methods; it seems that no one is really satisfying under "difficult" or non favorable preoperative anatomic conditions. How could an optimum operation method for a satisfying correction of a mild to moderate hallux valgus look like? The well known criteria for an optimally satisfying method to achieve full normalization of important forefoot parameters under all conditions should be a lateralization, plantarization and derotation of the Ist metatarsal head and also a normalization of the distal metatarsal articular angle (DMAA) in combination with a soft tissue correction. Methods: In order to achieve this outcome without the disadvantages of shortening or the need for unloading, we developed a new operation technique and new fixation devices. We performed a simple transverse lazy-L subcapital osteotomy and after an additional soft tissue release the Ist metatarsal head was restored to its preplaned optimum position in terms of narrowing the IM angle, plantarization, correction of the hallux valgus angle, derotation of a pronation 1 malrotation and improvement of the DMAA. Fixation was achieved with an intramedullary angel-stable transfixed $30 \mathrm{~mm}$ titanium plate. The rigidity of the implant rendered interfragmental compression or solid bone contact unnecessary. The goal was only an optimal correction. All patients were allowed to ambulate with full weightbearing immediately after the operation. Results: We retrospectively reviewed 346 patients (433 feet) who underwent subcapital osteotomy between May 2007 and December 2011; 308 were women and 38 men; their mean age was 65 years. The follow-up investigation was performed on average after 6.5 years ( 78 months); range 5.5 to 10 years (66 to 120
\end{abstract}


months). The AOFAS Score improved from 61.18 to $96.82(\mathrm{t}=55.13, \mathrm{p}<$ $0.001)$, the IM angle was reduced from $12.77^{\circ}$ to $4.21^{\circ}(t=89.70, p<0.001)$, the HV angle from $32.47^{\circ}$ to $7.75^{\circ}(t=51.68, p<0.001)$ The DMAA was improved from $20.84^{\circ}$ to $6.61^{\circ}(\mathrm{t}=29.34, \mathrm{p}<0.001)$. Minimal shortening of the first metatarsal $(0.33 \mathrm{~mm})$ and no recurrence of the deformity was observed. Conclusion: A new access to hallux valgus surgery is presented. Our results show that interfragmental compression between the osteotomy partners or good interfragmental contact is not necessary when a rigid intramedullary fixation device is used. The goal of this approach to hallux valgus surgery was to achieve excellent correction and a very rigid intramedullary angle-stable locked implant. The procedure yielded excellent results and was associated with no recurrence of hallux valgus.

\section{Keywords}

Hallux Valgus, Mild, Moderate, Toe Deformity, Lateralization, Plantarization, Derotation, Improvement of DMAA, Full Weightbearing, Hallux Valgus Surgery, New Access, Lazy-L Osteotomy, Soft Tissue Correction, IM-Angle, Angle-Stable Locking Screws, Intramedullary Locking Plate

\section{Introduction}

A normal intermetatarsal angle between the Ist and IInd metatarsal (IM-angle) is defined to be below $10^{\circ}$ and a normal hallux angle is a valgus of $15^{\circ}$ or less. Mild to moderate hallux valgus is marked by an IM-angle of $10^{\circ}-15^{\circ}$ and a hallux valgus angle of $16^{\circ}-30$ [1]-[7].

More than 150 methods have been described for correction of hallux valgus. The majority of these is a combination of a soft tissue and bone procedure. The bone cut is usually located in the intracapital or subcapital aspect of the first metatarsal head. A small number of methods include osteotomies in the shaft. Bone correction in the proximal aspect and arthrodesis of the TMT-I joint are reserved for larger IM angles and severe to extreme hallux valgus deformities [8]

The goal of any corrective osteotomy in combination with a soft tissue release is the reduction of a pathological Ist intermetatarsal angle and the correction of the hallux valgus angle. However, a number of additional parameters must be taken into account. Based on failed operations for hallux valgus, the following factors may be considered essential for the success of surgery:

- The length of the first metatarsal has to be preserved (or only slightly shortened in cases of a diminished ROM in the Ist MPJ). Shortenings may cause transfer metatarsalgia.

- A pathological DMAA must be normalized ( $<15^{\circ}$ valgus) [1] [7].

- A pathological pronation rotation has to be corrected.

- In case of metatarsus primus elevatus the head should be plantarized to normal.

The following additional factors which are beneficial for the patient and acce- 
lerate healing:

- Immediate mobility and immediate loading of the operated foot are essential for rapid bone healing and for avoiding stiffness, swelling and M. Sudeck.

- Avoiding the use of K-wires transfixing the MPJ I and protruding out of the toe for weeks, because they may cause stiffness, infection and they produce patient discomfort.

- No immobilization of the MPJ I with crutches or cast. Patients with much pain or swelling or children may use crutches for max. 3-5 days.

- No use of forefoot unloading shoes, but elastic shoes with full loading.

- Exercises as self treatment by the patient to increase the ROM of the Ist MPJ.

The five most popular methods for the correction of mild to moderate hallux valgus are the Austin-Chevron with modifications, open or percutaneous, Hohmann/Reverdin/Wilson with percutaneous modifications, Stoffella, Kramer/Bösch and Scarf (Table 1).

The most common operation is the Austin or distal Chevron introduced by Austin and Leventen in 1981. The advantages of this procedure are: Under ideal circumstances the procedure achieves a good correction of an IM angle up to $12^{\circ}$ to $14^{\circ}$ [9] [10] [11] [12] [13]. It is possible to plantarize and decompress the head by a second bone cut parallel to the upper branch of the V. This modification was described by Youngswick 1982 [14]. But the plantarization cannot be achieved stepless.

The disadvantages and potential problems include the fact that the operation permits practically no derotation of a pathological DMAA or correction of a pathological pronation. Due to fixation with a single screw, maximum bone contact is needed between the osteotomy partners, failing which the construction is unstable and may result in loss of correction. It may also be difficult to cut parallel $\mathrm{V}$ branches for a smooth shift. When the $\mathrm{V}$ is cut convergently the construction becomes unstable even with a screw. A divergent $\mathrm{V}$ renders shifting impossible. A shortening can occur up to $6.4 \mathrm{~mm}$, which leads in $2.7 \%-3.9 \%$ to transfer metatarsalgia [15] [16]. 5.56\% patients who received Chevron-Austin osteotomy needed revision [17] [18].

The potential of correction is not only limited by higher IM angles but also by the width of the metatarsal, so is the possibility of a shift shorter in a narrow bone than in a wider metatarsal. If the head is pushed too far to the lateral border, the construction gets unstable, despite the use of a screw.

Hohmann/Reverdin osteotomy was first described by Reverdin 1881 [19]. The transverse subcapital osteotomy is quite simple and provides a good correction of the IM angle up to $18^{\circ}$ and of an elevated DMAA. [20] [21] [22] [23]. Hohmann osteotomy is able to correct also rotational deformities and the head can be plantarized [21] [22]. So far Hohmann's method is able to correct all potential deformities. Wilson modification is a shortening osteotomy, directed from distal medial to proximal lateral. The osteotomy was originally unfixated and required a cast immobilization. Fixed with screws a cast was unnecessary but the patient 
had to restrict loading for 4 - 6 weeks.

Disadvantages: If the bone cut is not directed from medial proximal to distal lateral shortenings occur. The osteosynthesis requires unloading for 6 weeks [22]. The Hohmann operation is currently used by the percutaneous approach and most of the authors allow their patients the immediate full weightbearing [24] [25]. The use of a high-speed burr leads to a loss of bone and to shortening. $10 \%$ of the operations show elevation of the Ist metatarsal head [26].

The Stoffella osteotomy is a reverse Chevron osteotomy, the horizontal V is cut open to the front. The head can be shifted as far as to the lateral margin of the metatarsal, thus the correction potential is quite high. There is also a certain amount of derotating and DMAA correcting capacity. The fixation is provided by a special wire-like clip implant which is brought in intramedullary and the head is fixed by a screw to the clip-implant. Walking with weightbearing is allowed early [27]. The greatest problem of this implant and technique is the lack of fixation and stability intramedullary, so the implant is able to float proximally and shortenings up to $13 \mathrm{~mm}$ have been reported [28]. There may occur also dislocations of the transposed metatarsal head in $0.6 \%$ and arthrofibrosis $2.6 \%$ [27].

Kramer's osteotomy was used first by Kramer 1978 and described 1990. It is an extraarticular Hohmann osteotomy fixed with a K-wire introduced into the soft tissue of the entire great toe and after displacement of the head into the metatarsal [29] [30]. In 1990 Bösch described a percutaneous modification. The procedure is able to provide a good correction, because a full bone contact of the osteotomy partners is not necessary but a k-wire protrudes from the toe for 6 weeks and may lead to pin tract infections. The pin may cause discomfort for the patient and stiffness of the Ist MPJ due to the immobilization. The procedure does not permit the surgeon to move the head exactly to the desired position, but the head moves to a position which is given by the tissue circumstances, which is not always the optimum position. Elevation or plantar overcorrections of the metatarsal head were described. Bösch registered a pin tract infection in $10 \%$ while Ianno mentioned complications in 30\% of cases [31] [32] [33]

The Scarf osteotomy was described by Burutaran 1976 [34]. It is a Z-shaped shaft osteotomy which is employed for mild to moderate and also for more severe Hallux deformities. It provides correction up to an IM angle of about $16^{\circ}$, and is able to correct higher IM angles than the Chevron [35]. The DMAA can also be improved. The problems are shortening, troughing, a limited potential of correction and almost no potential of correction of a mal pronation. The operation is technically very demanding and is associated with a complication rate of $19 \%$, as reported by Crevoisier 2001 with reoperations needed up to $11 \%$ [36]. To quote Coetzee 2003: "Scarf osteotomy has multiple potential pitfalls", he described complications in $47 \%$ [37].

There is not one operation described in literature, which meets all the desired criteria without significant disadvantages [38]. Each procedure yields excellent 
results if the circumstances fit exactly to the profile of the special procedure but it seems to be lack of a method which really meets all this criteria in one single osteteotomy and fixation [24] [37] [39].

Xiaojun Duan wrote 2011 [40]: "The rate of complications in hallux valgus surgery ranges from $10 \%$ to $55 \%$. No single procedure can be recommended given the complexity of the deformity." The rates of reoperations range from $5 \%$ to $9 \%$ [17].

\section{Materials and Methods}

In the years 2006 and 2007 we tried to develop or modify an operation method to come as close as possible to an optimum correction of all criteria which lead to the mild to moderate hallux valgus. The mild to moderate hallux valgus is the most common deformity of the foot. The correction had to address the relevant criteria and avoid the use of K-wires that would immobilize the first MPJ or protrude from the toe, in addition to ensuring no shortening of the metatarsal. The patients should ambulate immediately after the operation with full weighbearing in an elastic comfort shoe.

In order to fulfill these criteria without any accompanying disadvantages, we had to look for a new operation technique and new fixation devices. We developed a set of $30 \mathrm{~mm}$ long intramedullary located and angle stable from cortex to cortex transfixed titanium plates. These plates are fixed intramedullary and the osteotomised metatarsal head is mounted in a angle stable manner on the head of the plate (Figure 1).

The head can be placed in stepless fashion in optimum position in terms of lateralization, plantarization, derotation, improvement of DMAA regardless the quality of contact between the bone partners.

There are plates with different offsets available, which permit the head to be shifted $0 \mathrm{~mm}, 2 \mathrm{~mm}$ or $4 \mathrm{~mm}$.

\section{Surgical Technique}

The operation can be performed by the open procedure with an incision of

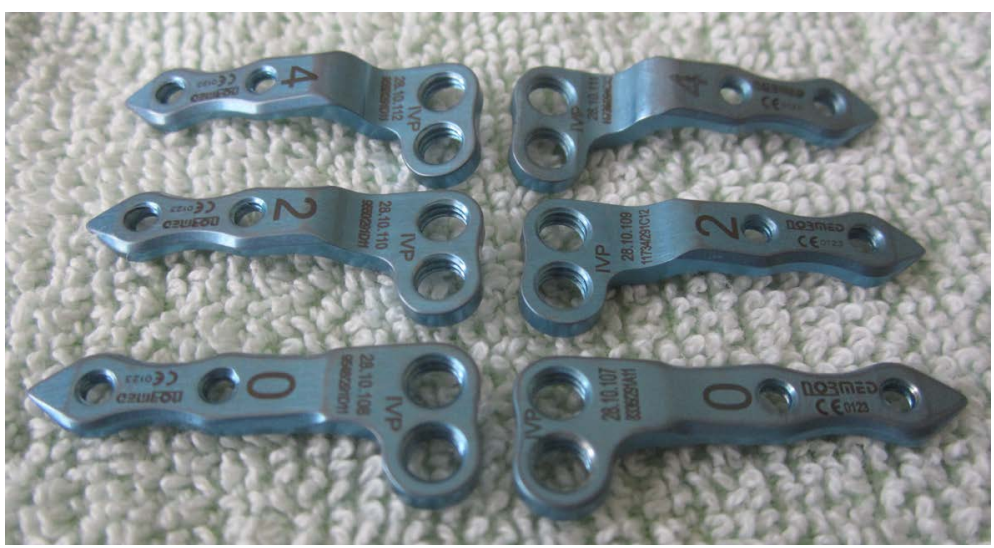

Figure 1. Intramedullary locking plates (V-tek System) with offsets $0 \mathrm{~mm}, 2$ $\mathrm{mm}$ and $4 \mathrm{~mm}$. 
Table 1. Advantages and disadvantages of the most popular operations for mild to moderate hallux valgus.

\begin{tabular}{|c|c|c|c|c|c|c|c|c|c|}
\hline $\begin{array}{l}\text { Name of } \\
\text { procedure }\end{array}$ & Lateralization & Plantarization & $\begin{array}{l}\text { DMAA } \\
\text { correction }\end{array}$ & $\begin{array}{l}\text { Derotation } \\
\text { of over } \\
\text { pronation }\end{array}$ & Immobilisation & $\begin{array}{l}\text { Unloading } \\
\text { for } 6 \text { weeks }\end{array}$ & k-wire & $\begin{array}{c}\text { Severe } \\
\text { shortening } \\
\text { can occur }\end{array}$ & $\begin{array}{c}\text { Other } \\
\text { Problems }\end{array}$ \\
\hline Austin-Chevron & only half width & $\begin{array}{l}\text { yes but not } \\
\text { stepless }\end{array}$ & $\begin{array}{c}\text { very } \\
\text { difficult }\end{array}$ & no & no & no & no & yes & $\begin{array}{c}\text { Low } \\
\text { correction } \\
\text { potential }\end{array}$ \\
\hline $\begin{array}{c}\text { Hohmann/ } \\
\text { Reverdin/Wilson }\end{array}$ & fair & yes & yes & yes & yes & yes & no & yes & \\
\hline Stoffella & good & $\begin{array}{l}\text { yes but not } \\
\text { stepless }\end{array}$ & yes & no & no & no & no & yes & $\begin{array}{l}\text { Implant has to } \\
\text { be removed }\end{array}$ \\
\hline Kramer/Bösch & good & questionable & yes & yes & no & no & yes & yes & $\begin{array}{l}\text { Malposition of } \\
\text { MT I, MPJ } \\
\text { Immobilisation }\end{array}$ \\
\hline Scarf & fair & $\begin{array}{l}\text { difficult, not } \\
\text { stepless }\end{array}$ & yes & no & no & no & no & yes & $\begin{array}{l}\text { Troophing, } \\
\text { quite difficult } \\
\text { bone cut }\end{array}$ \\
\hline
\end{tabular}

about 4 to $5 \mathrm{~cm}$, or by a minimally invasive approach with an incision of about 2 $\mathrm{cm}$, with two additional stab incisions. After incision of the capsule the pseudoexostosis is removed and a bone cut is performed subcapitally as a transverse osteotomy with a lazy $\mathrm{L}$ at the plantar third of the Ist metatarsal (Figure 2).

A soft tissue release was performed in all cases. The head is now transposed to the best position. Using an inserter, the plate is positioned in the intramedullary space. The insertion is usually very simple. The inserter is also a target device for drilling and screwing. The lateral and medial cortex is drilled now from the lateral aspect, drilling through holes in the plate (Figure 3).

There are two threaded holes in the proximal part of each plate. The drill diameter is $2 \mathrm{~mm}$ and the screw diameter is $2.7 \mathrm{~mm}$. The screws fix the plate angle-stable, due to the corresponding threads in the plates. Screw lengths are 14 to $16 \mathrm{~mm}$ in most cases. The distal fragment is then aligned and all parameters are corrected. The plate has an L-shaped head with threaded holes for two $2.7 \mathrm{~mm}$ screw heads. After the distal fragment is drilled with a $2 \mathrm{~mm}$ drill, the head of the first metatarsal is now screwed in a angle stable manner to the plate head. The screw length here is usually $18 \mathrm{~mm}$. Given the extremely rigid fixation only a point contact is adequate (Figures 4-6).

As a result, a shift of $100 \%$ is possible. The distal bone fragment can be placed literally "next to" the proximal one. No k-wires are used [41]. In cases of interphalangeal hallux valgus an Akin osteotomy is performed [42] (Figures 7-11).

The osteosynthesis can be fully loaded immediately after surgery and patients can resume their usual activities immediately using postoperative flexible and elastic so-called "medic ballerinas" (Figure 11(a)).

The majority of patients were treated under local anaesthesia (Bier block) and we used a tourniquet in nearly all cases. Approximately $75 \%$ were outpatients and left the unit after an observation period of about 3 hours. The aftertreatment began the next day. X-ray were performed and the dressing changed. The further changing of the dressing was than performed weekly. After two weeks the patient 


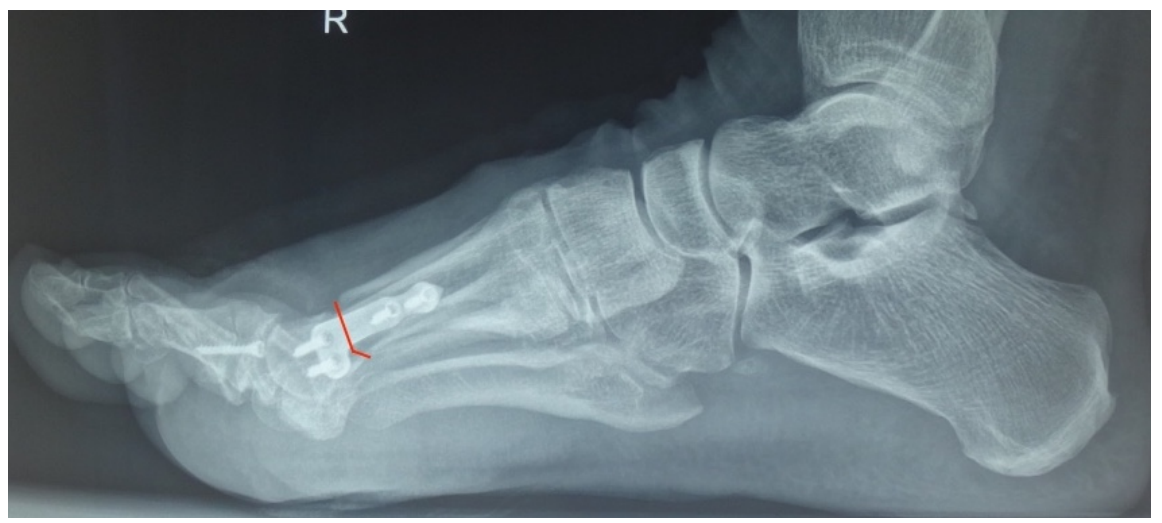

Figure 2. Shape of bone cut.

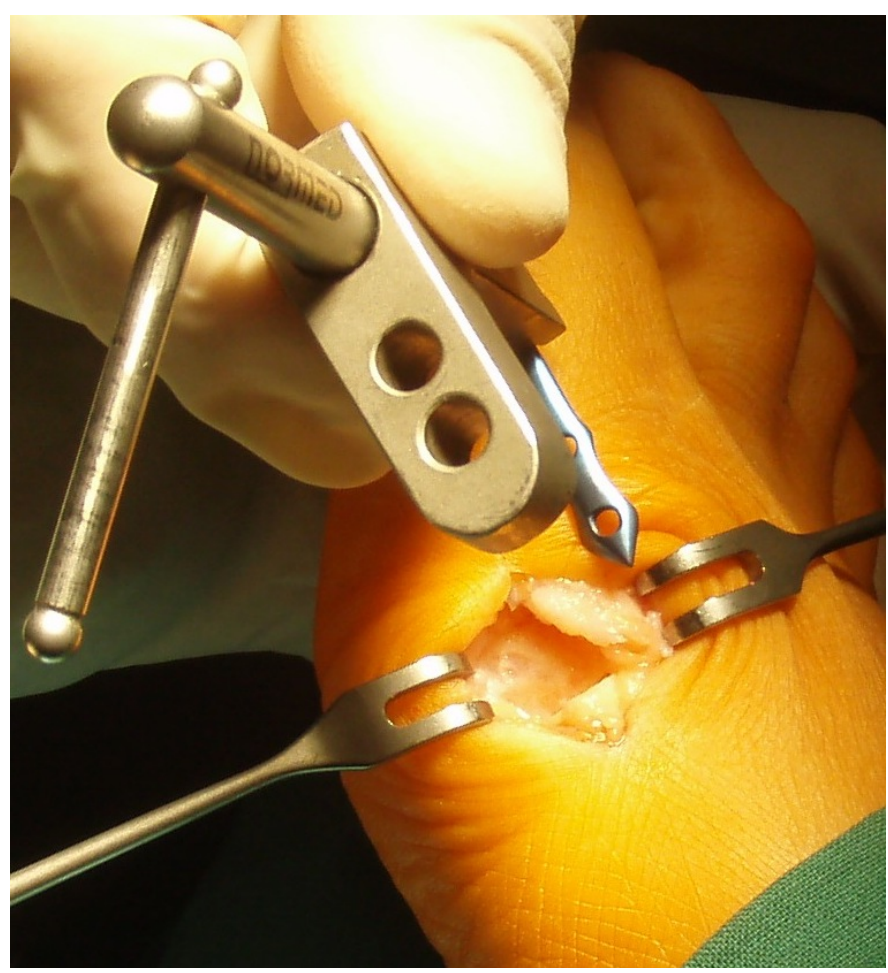

Figure 3. Inserter/Target device for drilling and screwing.

was taught to apply redressing tapes on his/her own. Patients had to mobilize the Ist MTP joint to increase the ROM by performing exercises. Walking with full weight bearing was allowed immediately after the operation. Most of the patients wore the "medic ballerina" which is a very elastic comfort shoe, we developed with a shoe company. 6 weeks after the operation a x-ray documented the bone healing. Running and tipped shoes were permitted after 3 month (Figures 12-17).

\section{Results}

We included 346 patients with 433 operated feet into this retrospective study. The patients were operated between May 2007 and December 2011. There were 


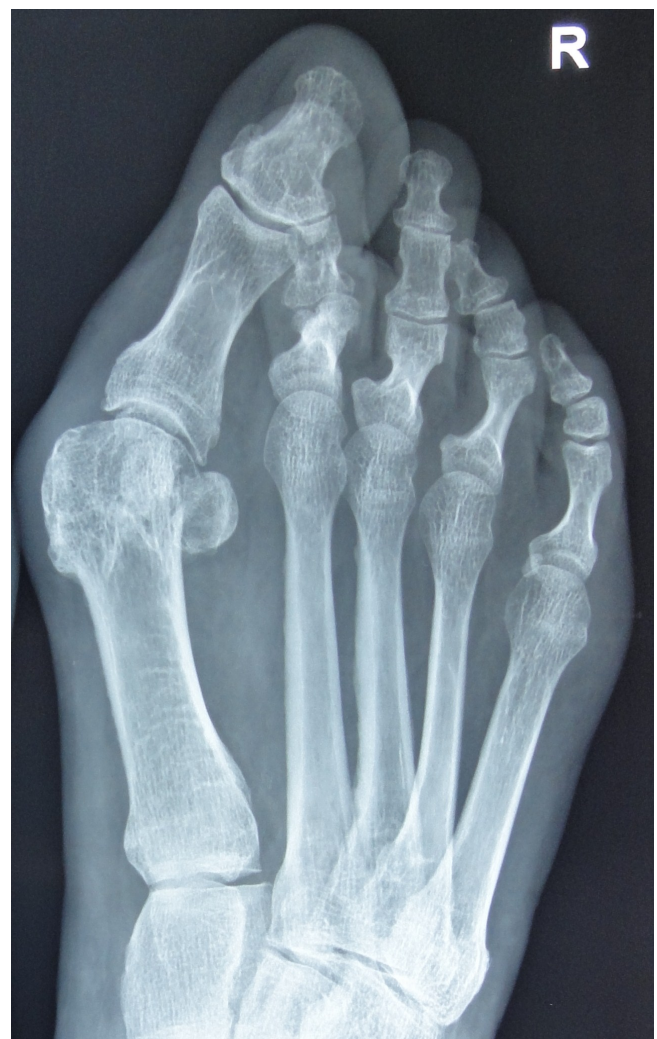

Figure 4. Patient Nr. 1: Recurrance of preoperated hallux valgus and hammertoe II.

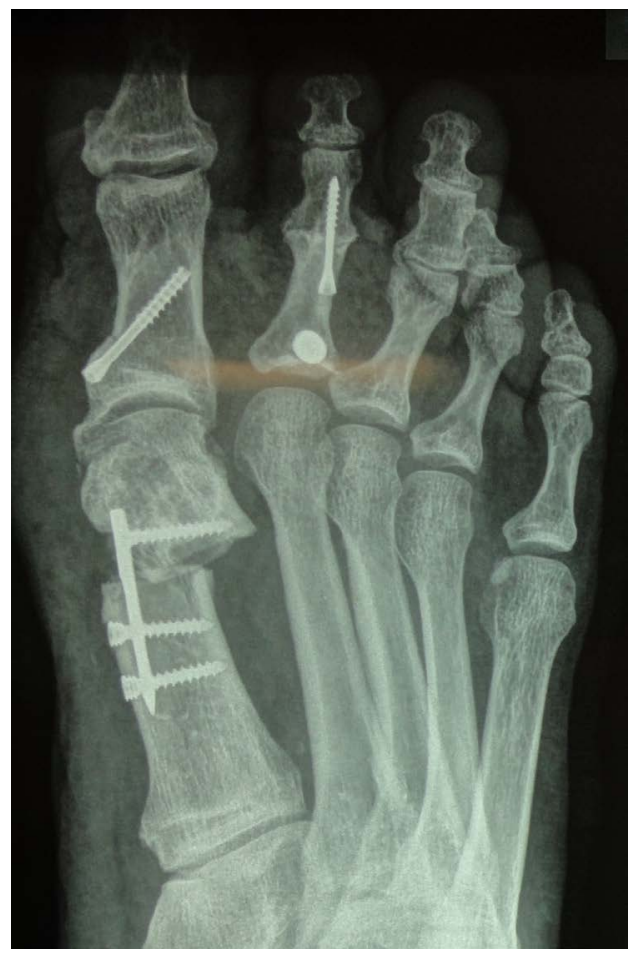

Figure 5. Patient Nr. 1. Correction of a pathological DMAA without loss of length. Distal fragment has only a point contact to the proximal bone partner. Additional Akin osteotomy and PIP arthrodesis and FDL tranfer on the 2nd toe. 


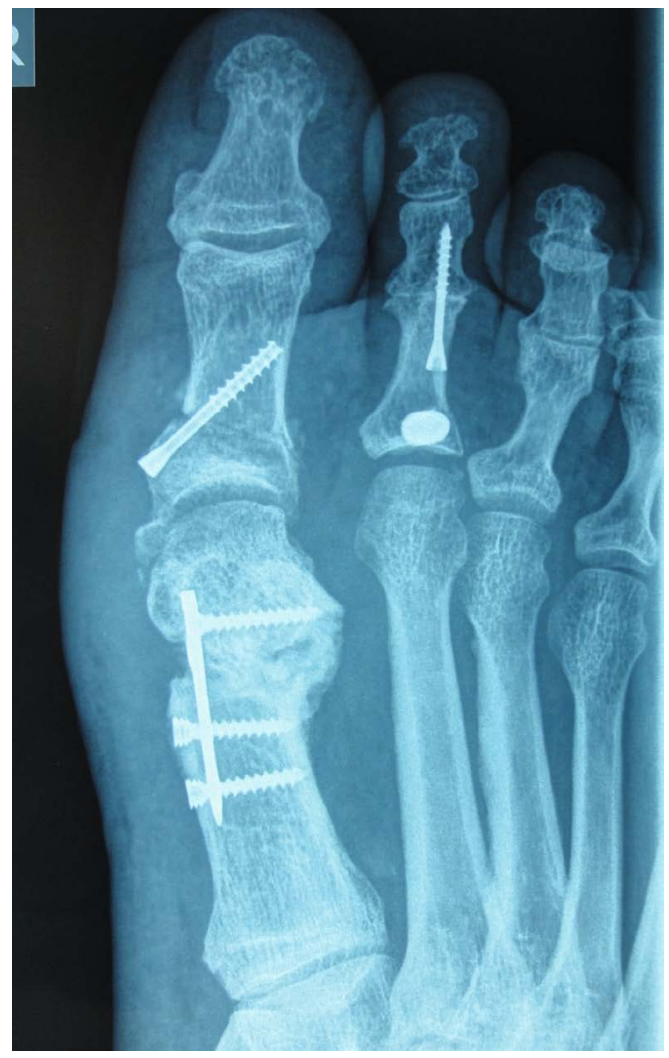

Figure 6. Patient Nr. 1. After 6 months the bone healing is completed with no loss of correction. Immediate full weigh bearing was allowed.

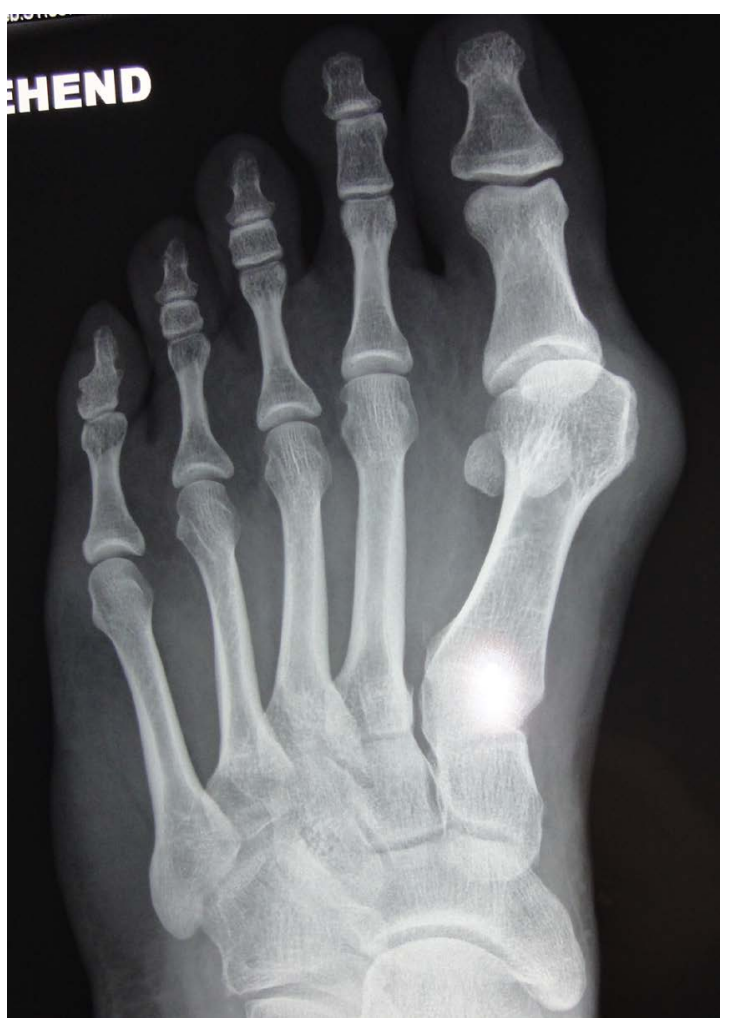

Figure 7. Patient Nr. 2. Hallux valgus with subluxed Ist MPJ and pathological DMAA. 


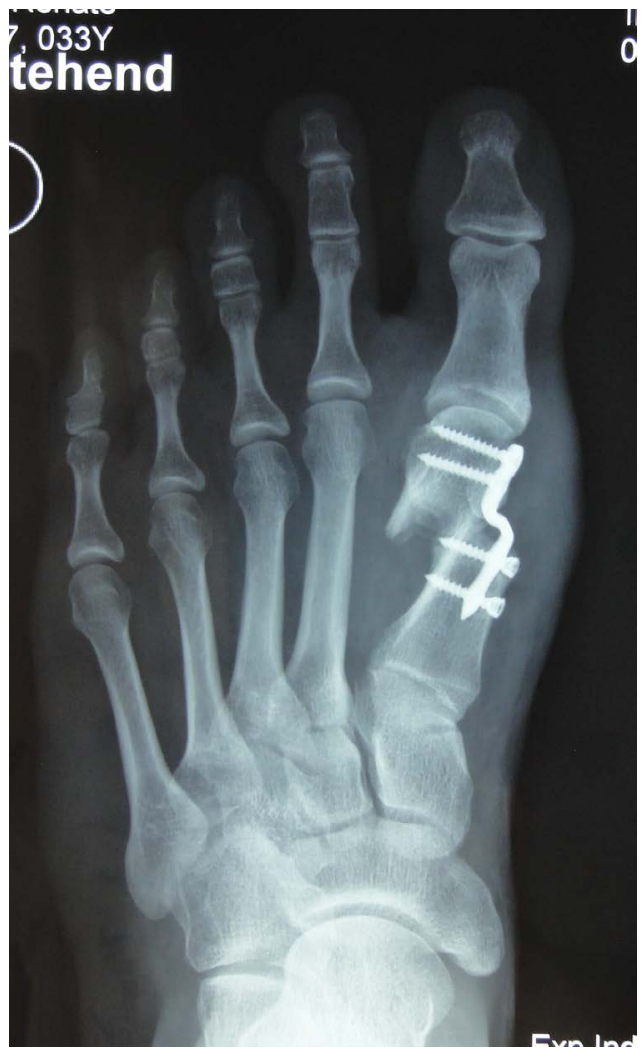

Figure 8. Patient Nr. 2: Correction with $100 \%$ lateralization and only point contact of the osteotomy partners.

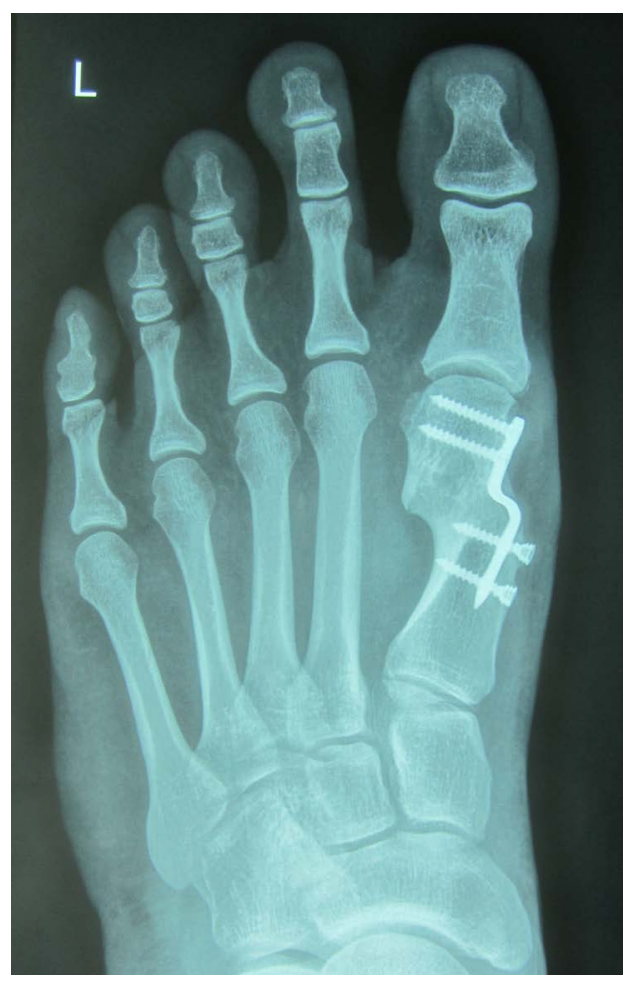

Figure 9. Patient Nr. 2. Result after 7 years. All components are corrected, no loss of lenght. Immediate full weight bearing, running after 8 weeks. 


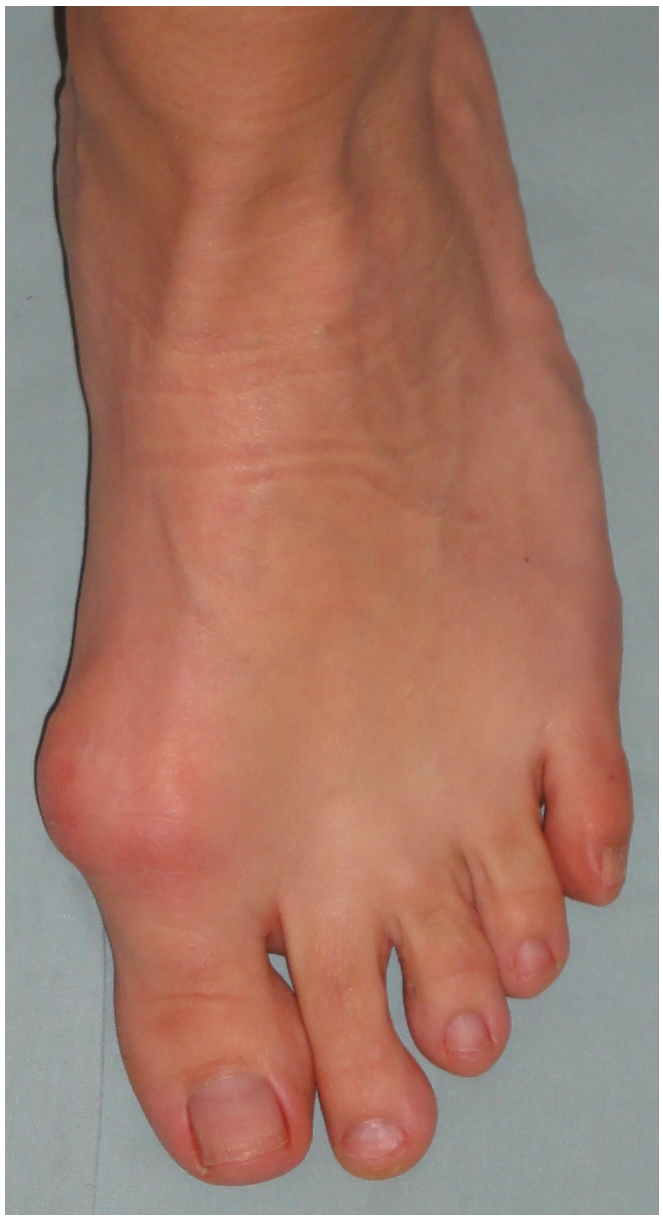

Figure 10. Patient Nr 2. Clinical appearance before the operation.

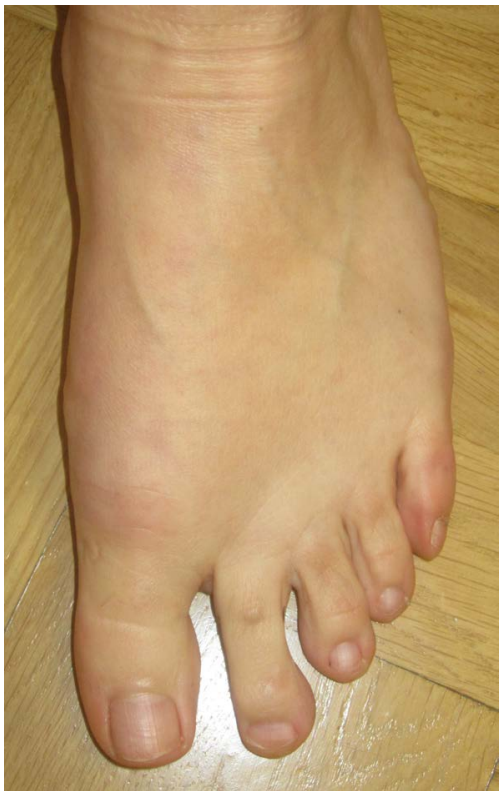

(a)

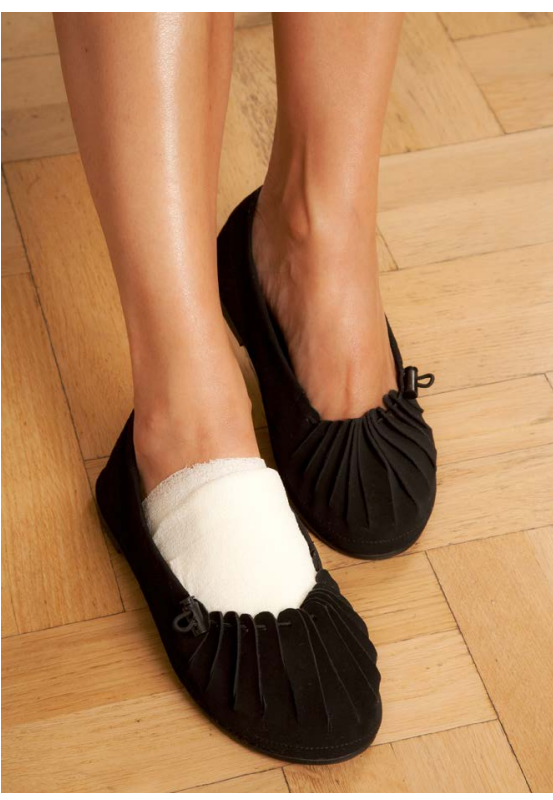

(b)

Figure 11. (a) Patient Nr. 2. Result after 7 years; (b) Medic ballerina for undisturbed walking with bulky dressing or swellings 


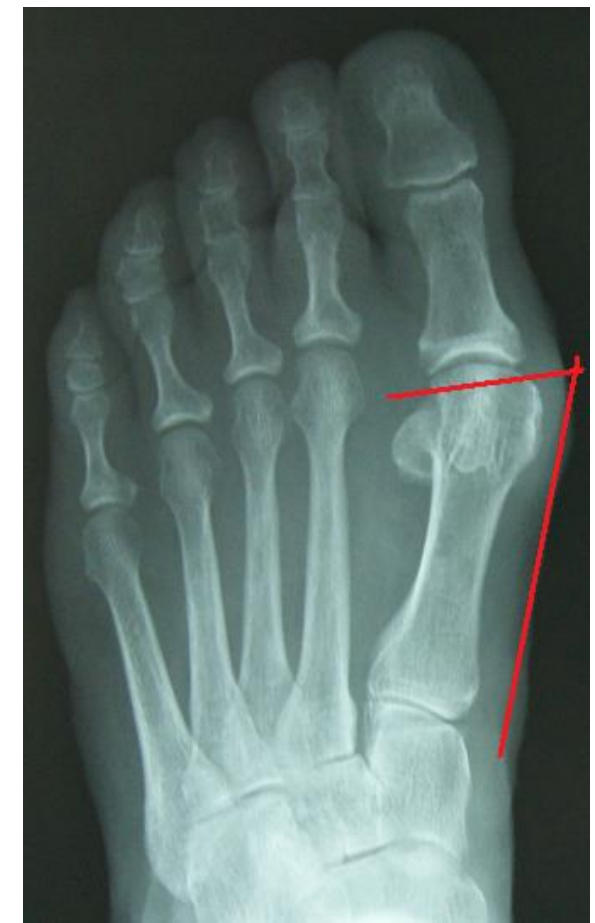

(a)

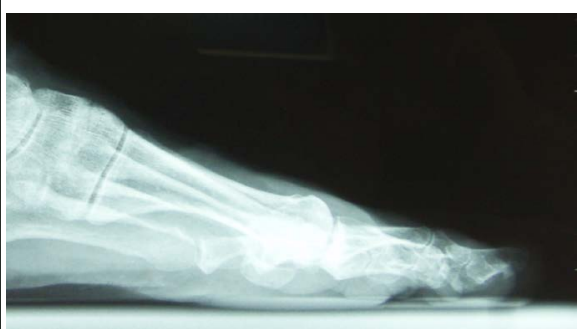

(b)

Figure 12. (a) Patient Nr. 3. Hallux valgus, pathologic DMAA; (b) Patient Nr. 3 Elevation of the Ist metatarsal of $3 \mathrm{~mm}$.

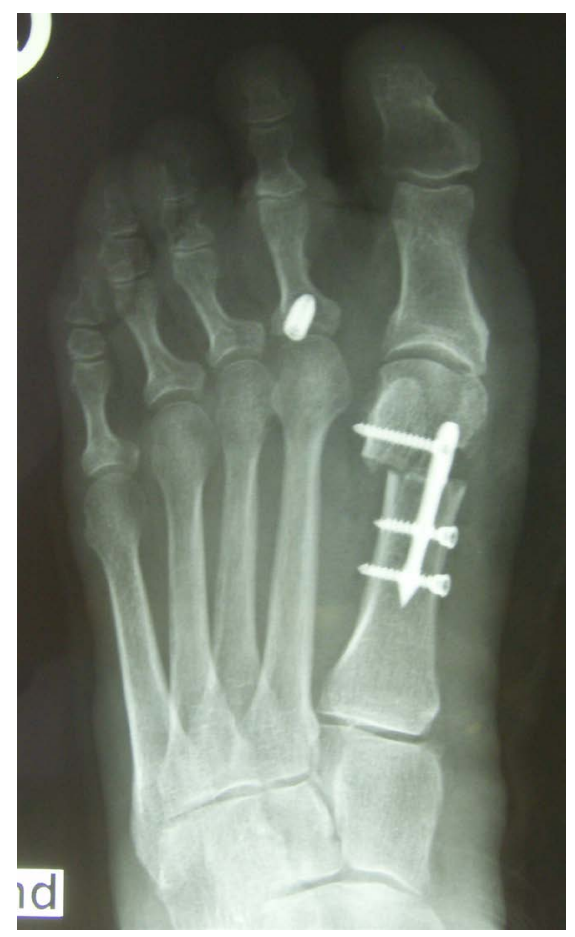

Figure 13. Patient Nr. 3 Correction of the IM angle by lateralization, of the DMAA by derotation (lateral opening wedge), the head was also plantarized and a pronation malrotation was corrected. There is only a minimal contact between the osteotomy partners. A FDL Transfer was performed on the 2nd toe. Fixation with an interference screw. Immediate full weight bearing. 


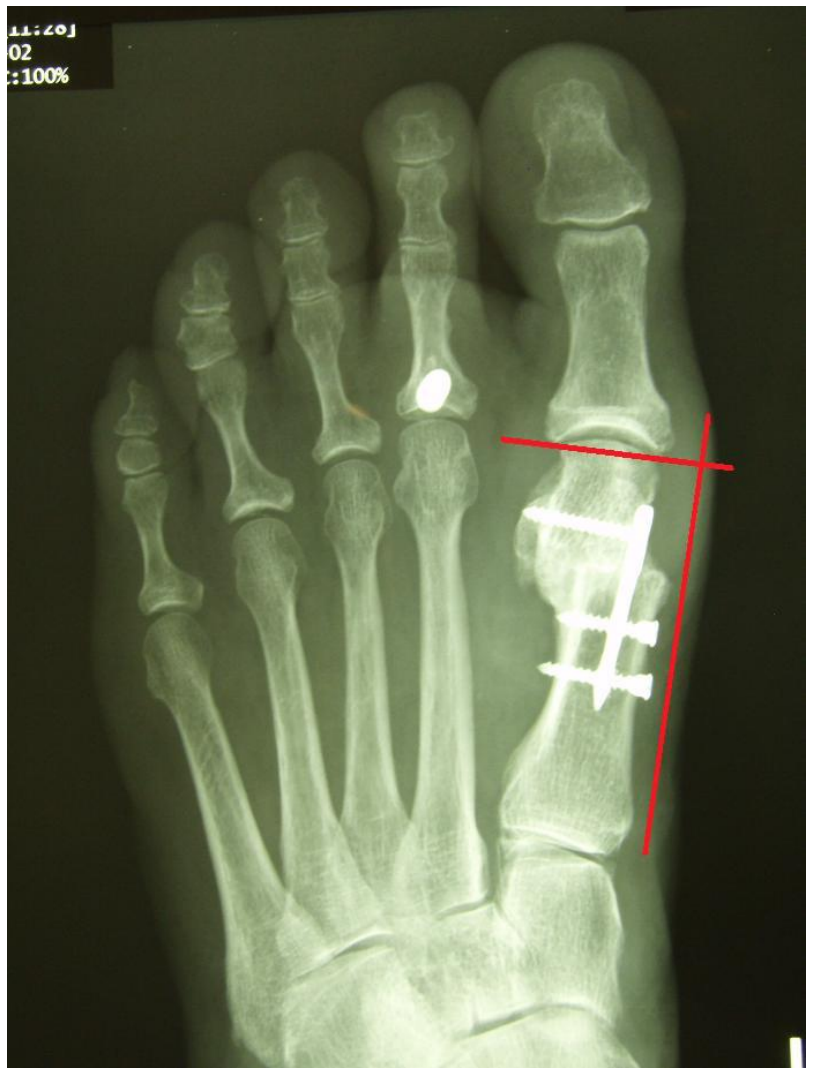

Figure 14. Patient Nr. 310 years result with complete correction of DMAA and all other components. No shortening of the Ist metatarsal.

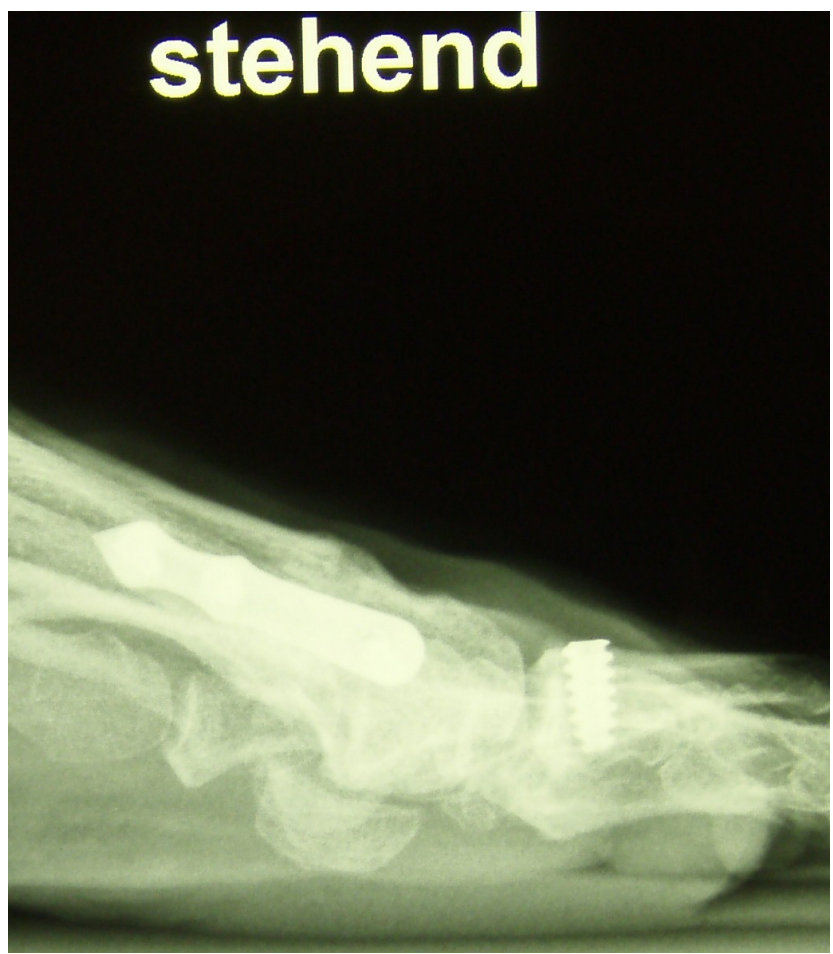

Figure 15. Patient Nr. 3. The elevation of the I metatarsal was equalized by plantarization of the head of $3 \mathrm{~mm}$. 


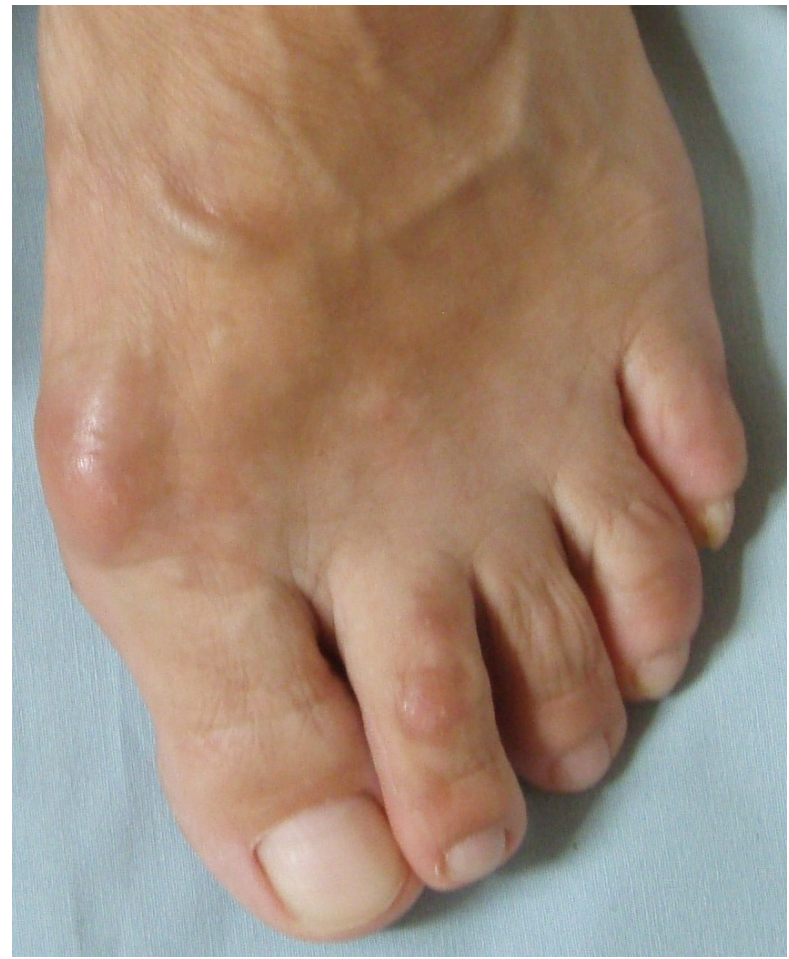

Figure 16. Patient Nr. 3. Clinical appearance of mild but painful hallux valgus, Flexible Hammertoe II.

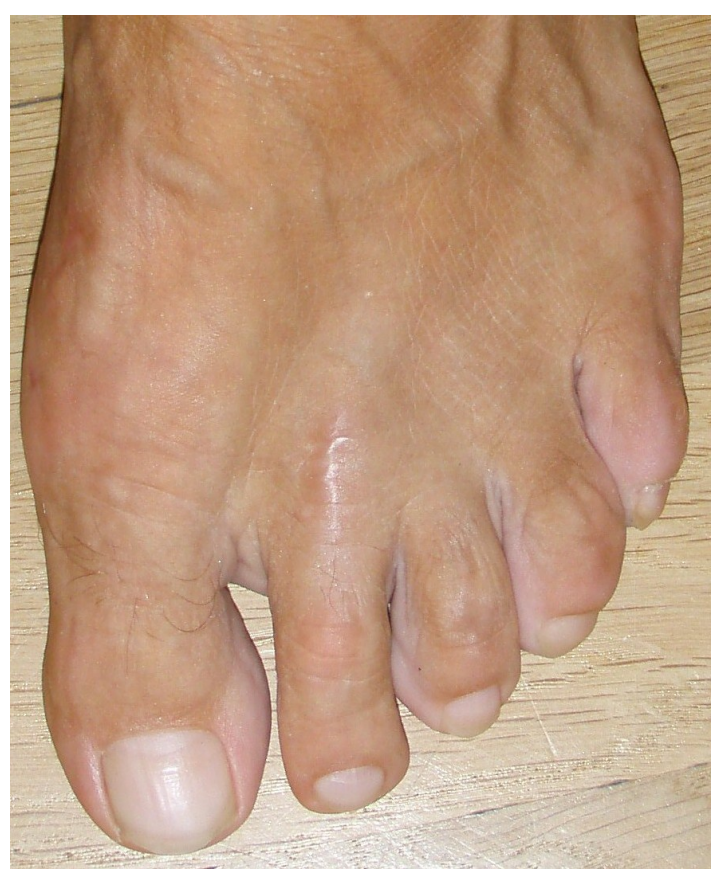

Figure 17. Patient Nr. 3. 10 years result. Painfree, full function, good cosmetic outcome.

308 females and 38 males. $70.8 \%$ (245 patients) underwent simultaneously other forefoot surgery like Akins, FDL-Transfers and PIP arthrodeses for hammertoes, metatarsal shortening ostetomies for the lesser metatarsals or repair of tailors 
bunions. Ages ranged from 13 to 88 years (mean age 65 years). The follow up was performed after 6.5 years ( 78 month), from 5.5 years to 10 years ( 66 to 120 month) (Figures 18-31).

We documented pre- and postoperatively and in the follow up evaluation for this study the following parameters: AOFAS Score, the IM angle, the HV angle, the DMAA angle, the angle of pronation rotation of the big toe, the circumference of the foot in the area of the metatarsal heads, the plantarization of of the first metatarsal and the amount of shortening of the first metatarsal. X-rays were

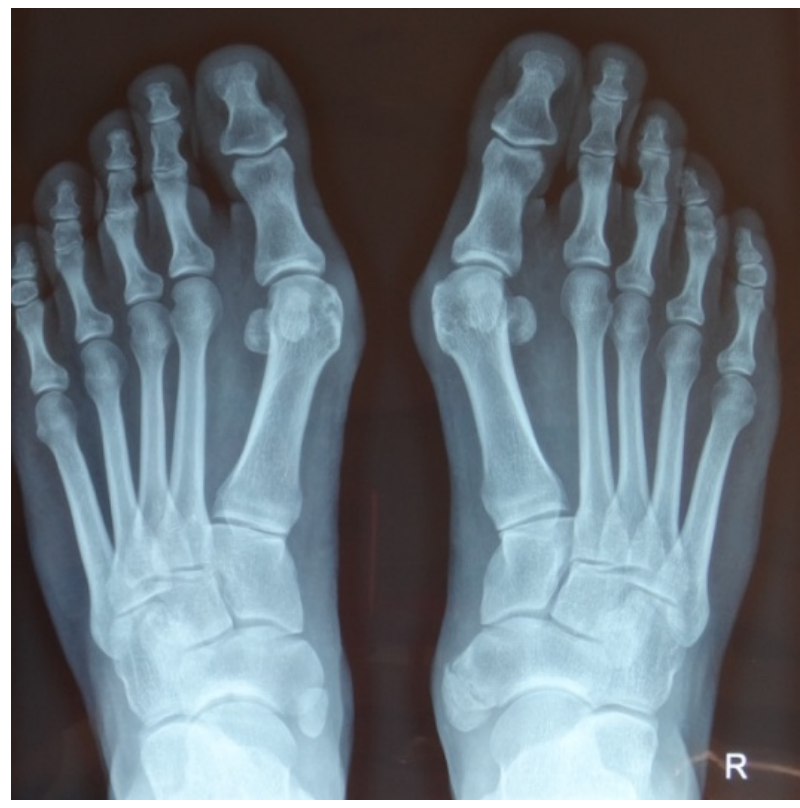

Figure 18. Patient Nr. 4. Bilateral moderate hallux valgus.

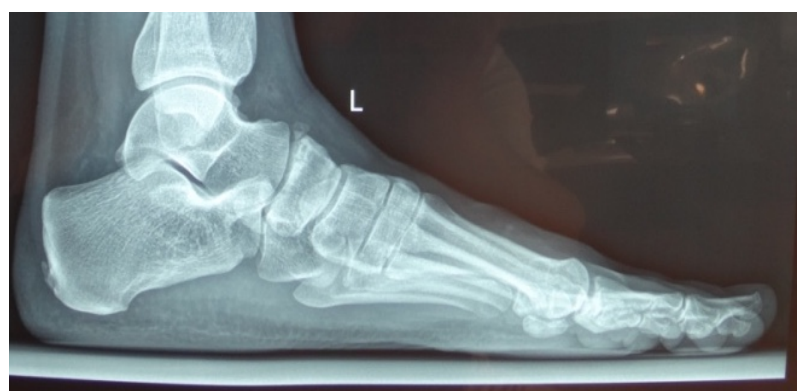

Figure 19. Patient Nr. 4. Side view left foot.

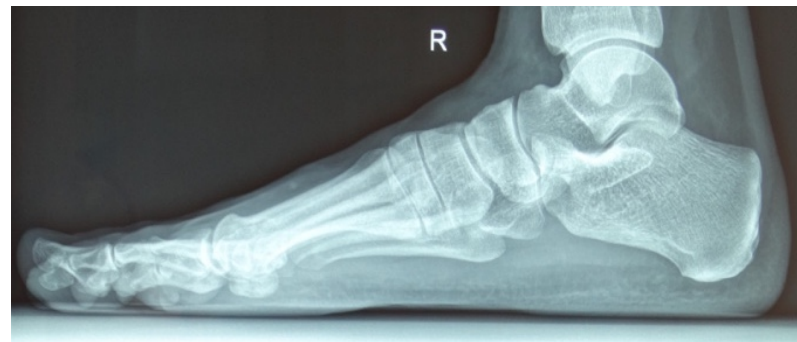

Figure 20. Patient Nr. 4. Side view right foot. 


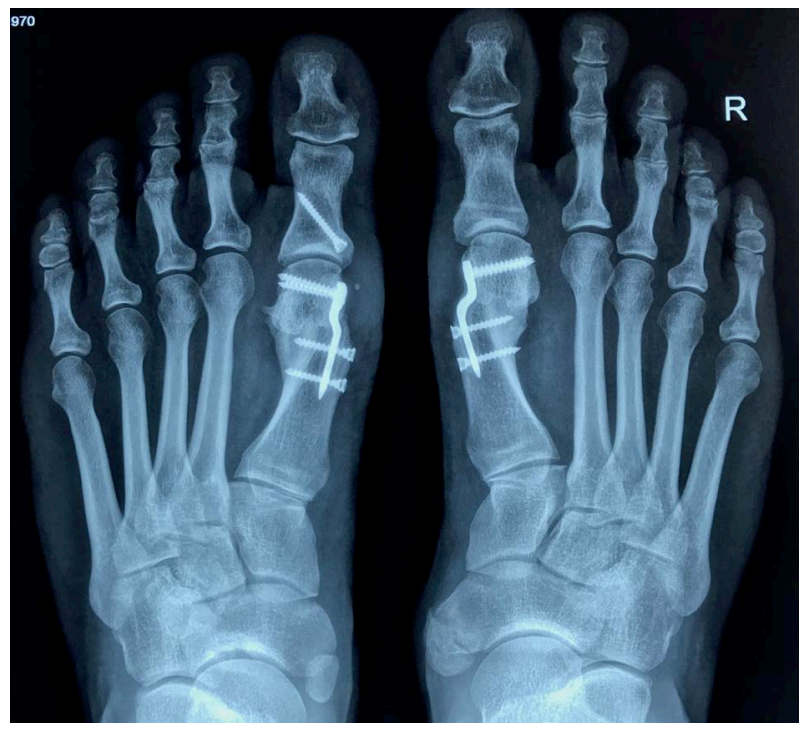

Figure 21. Patient Nr. 4. 5 years after bilateral correction. Outpatient. Immediate full weight bearing.

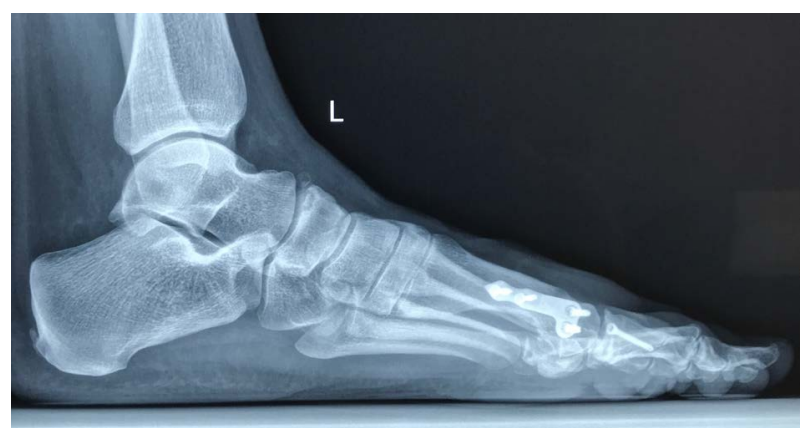

Figure 22. Patient Nr. 4. Side view of the left foot shows the plantarization of $2 \mathrm{~mm}$.

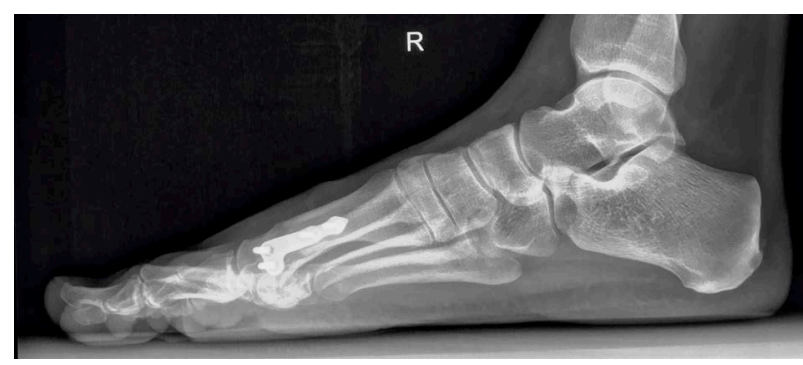

Figure 23. Patient Nr. 4. Side view of the right foot shows the plantarization of $2 \mathrm{~mm}$.

performed preoperatively, 1st day postoperatively, 6 weeks post operation and at the follow up. The patients were asked about their satisfaction with the operation. As analysis method we used the t-test.

The AOFAS Score improved from 61.18 (between 24 and 80) to 96.82 (between 87 and 100) which is highly significant $(t=55.13 \mathrm{p}<0.001)$ (Table 2. Figure 32, Figure 33). 
Table 2. AOFAS before and after OP.

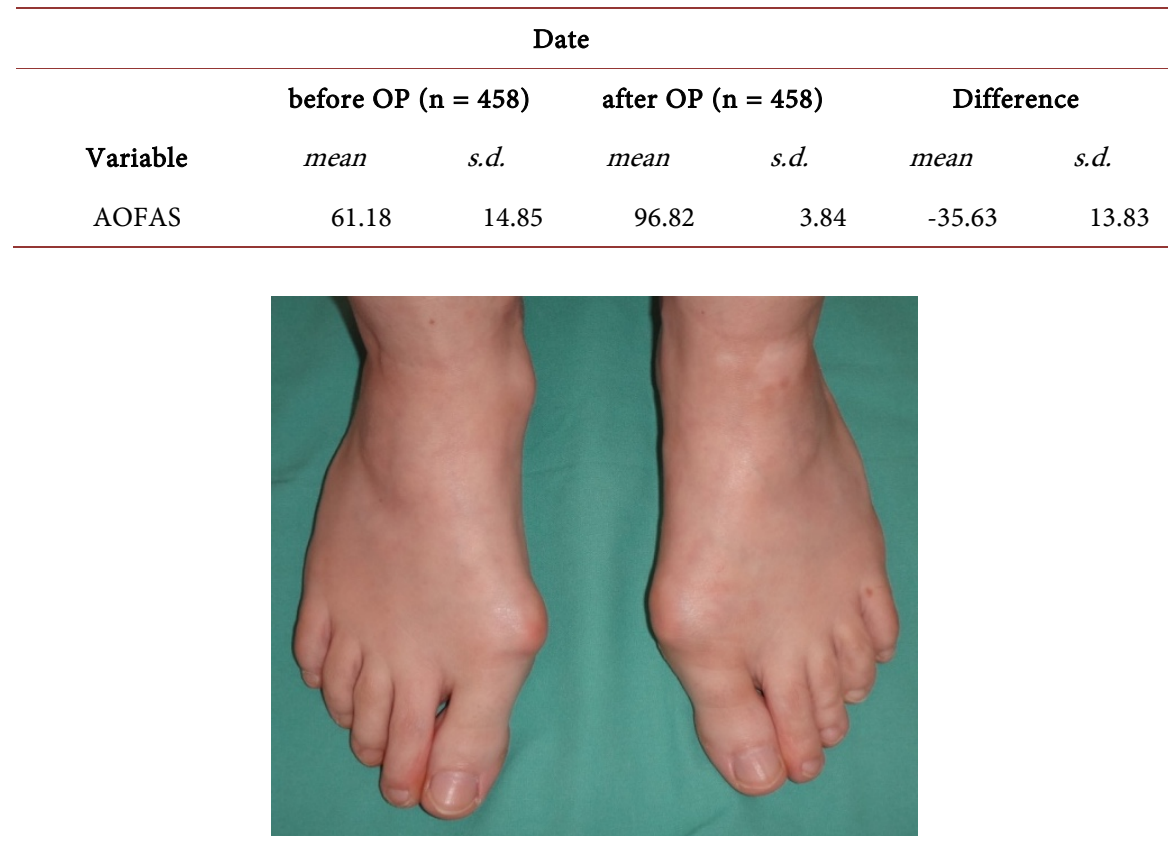

Figure 24. Patient Nr. 4: Preoperative clinical view.

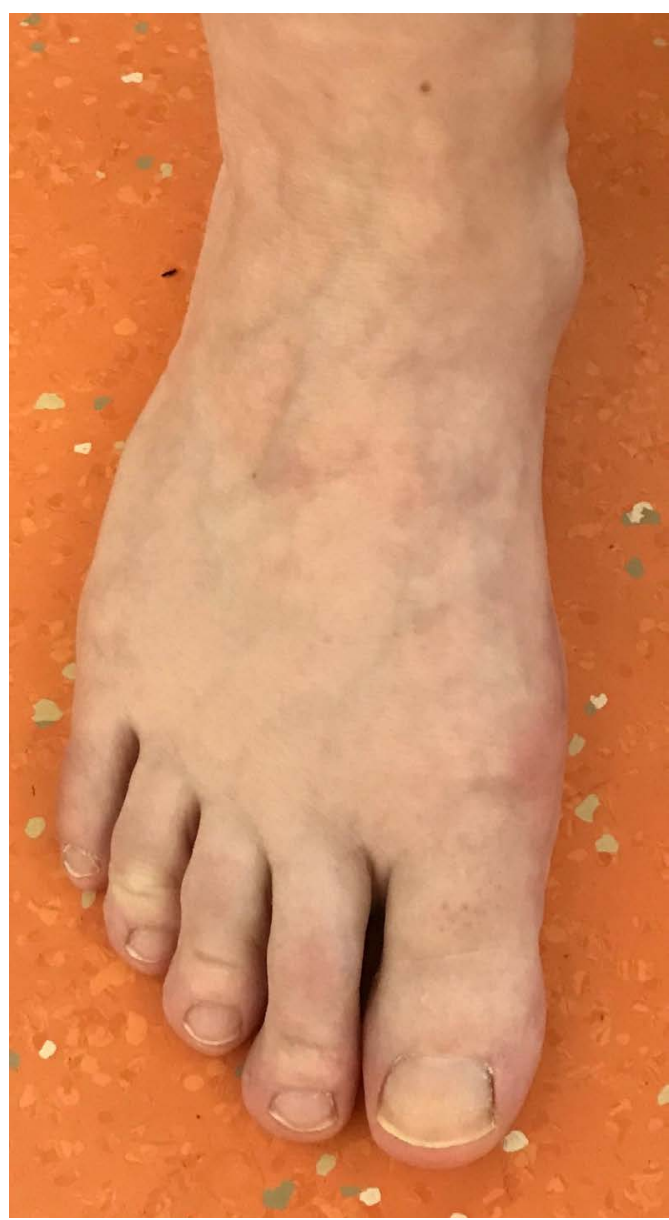

Figure 25. Patient Nr. 4: Postoperative clinical view. 


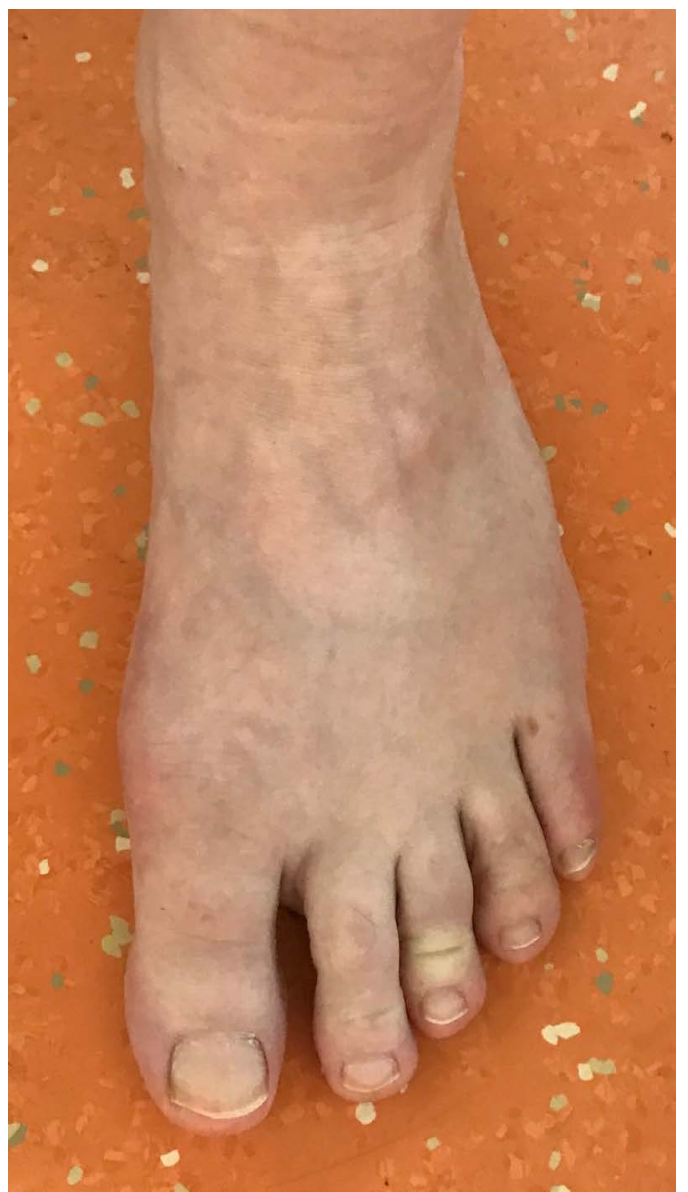

Figure 26. Patient Nr. 4: Postoperative clinical view.

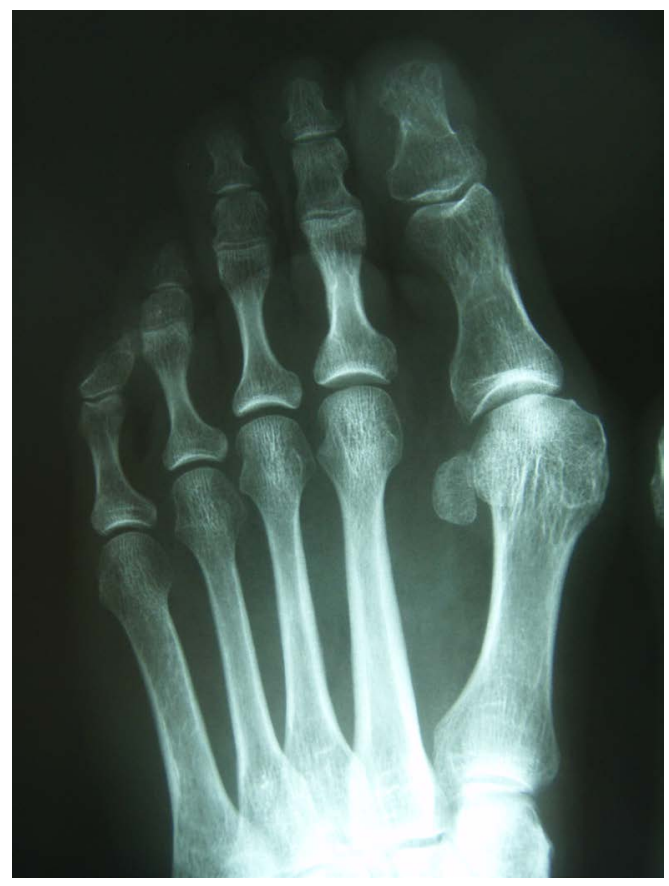

Figure 27. Patient Nr. 5: Hallux valgus with pronation, elevation, malrotation and pathological DMAA. 


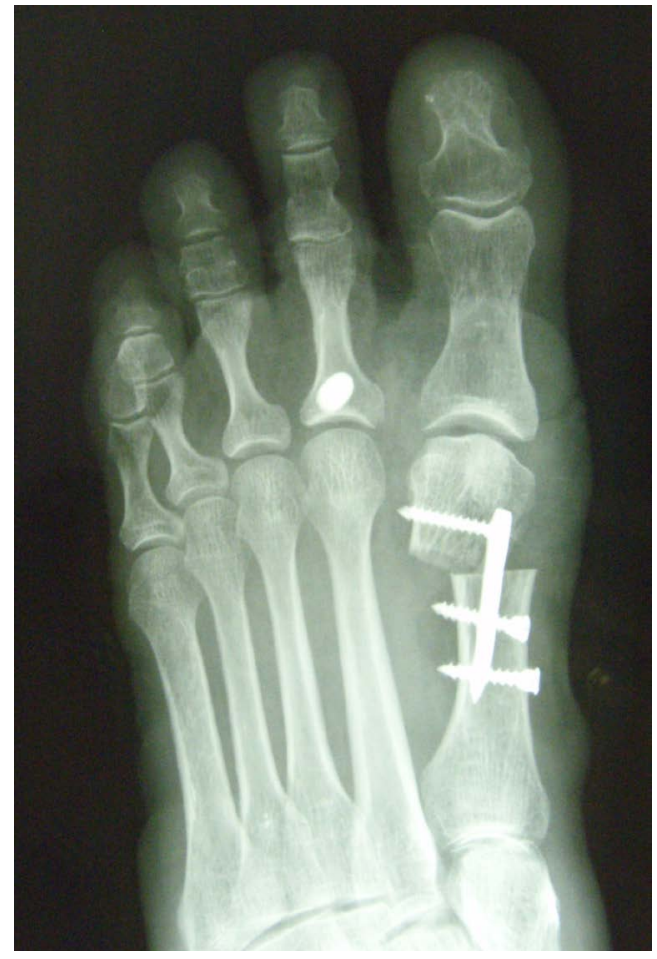

Figure 28 Patient Nr. 5: Correction of all components, only partial contact of bone partners, additional FDL Transfer II for a flexible hammertoe II.

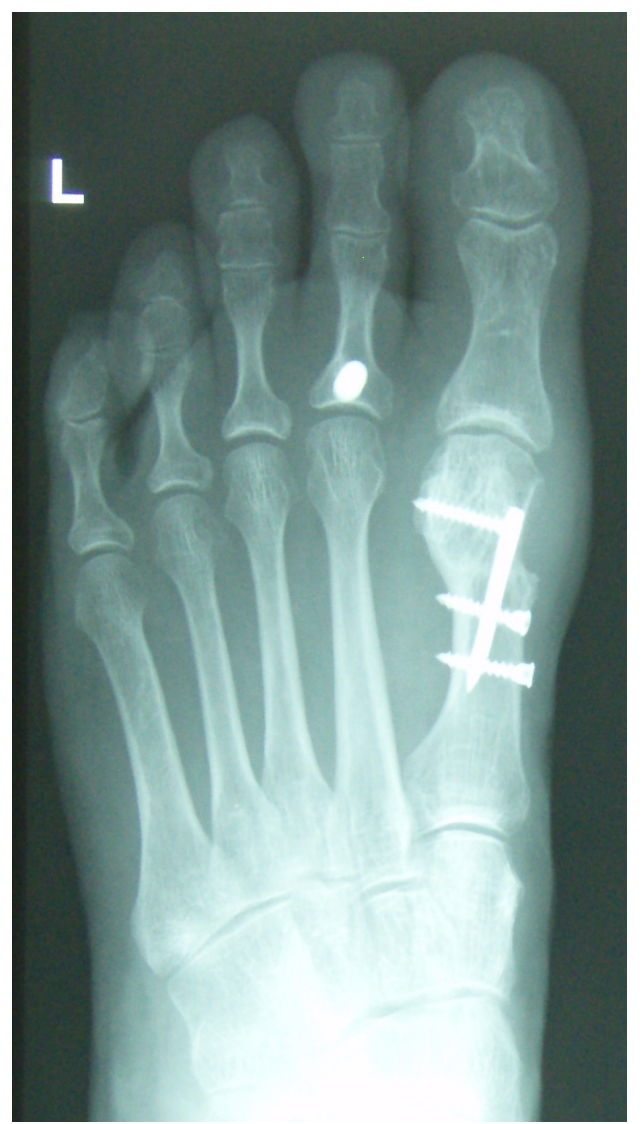

Figure 29. Patient Nr. 5. Result after 8 years. 


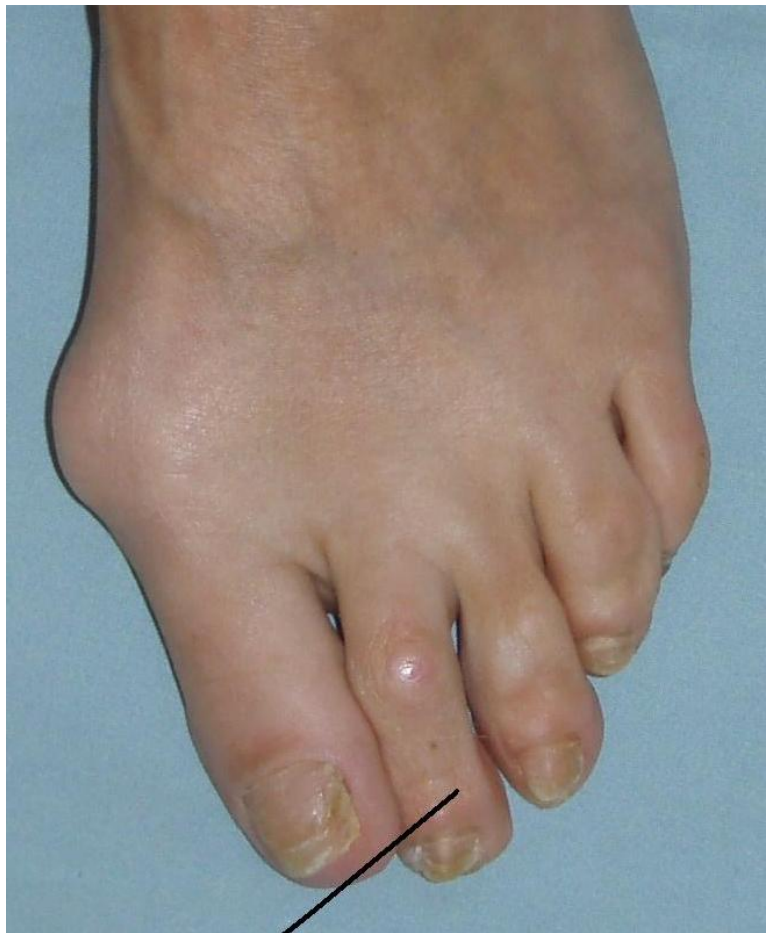

Figure 30. Patient Nr. 5: View of the foot preoperative, Pronation $40^{\circ}$.

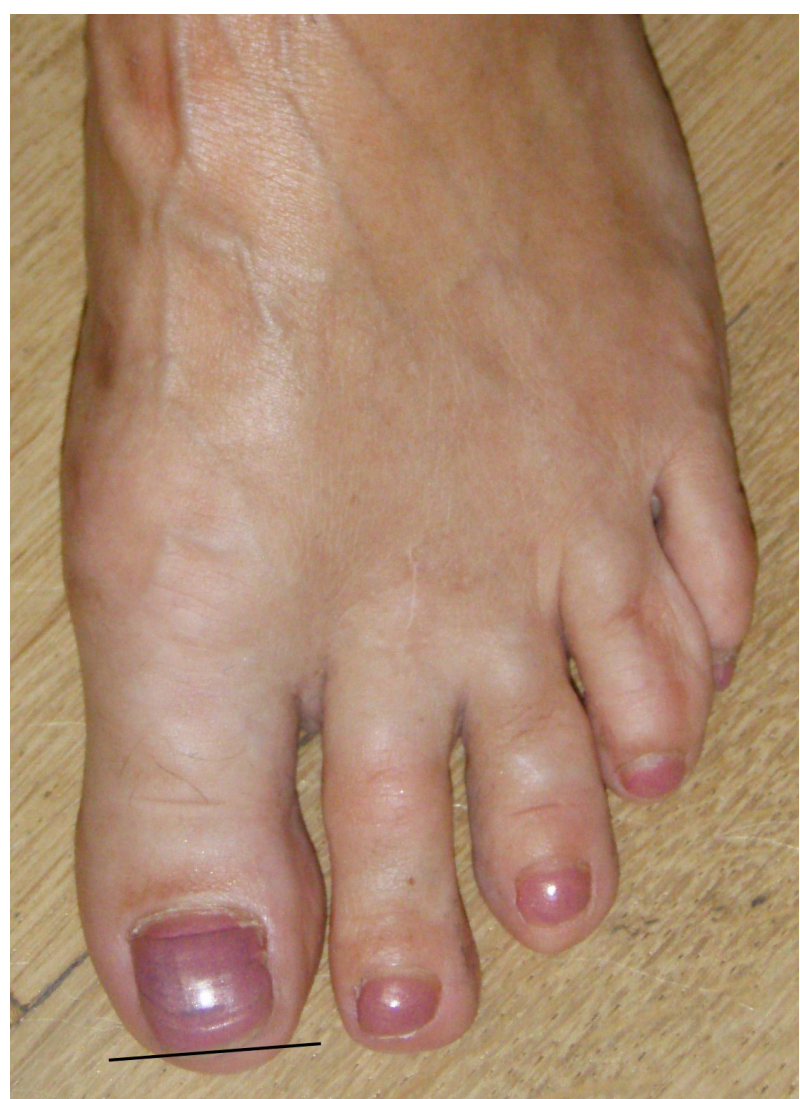

Figure 31. Patient Nr. 5: View of the foot postoperative, Pronation corrected. 


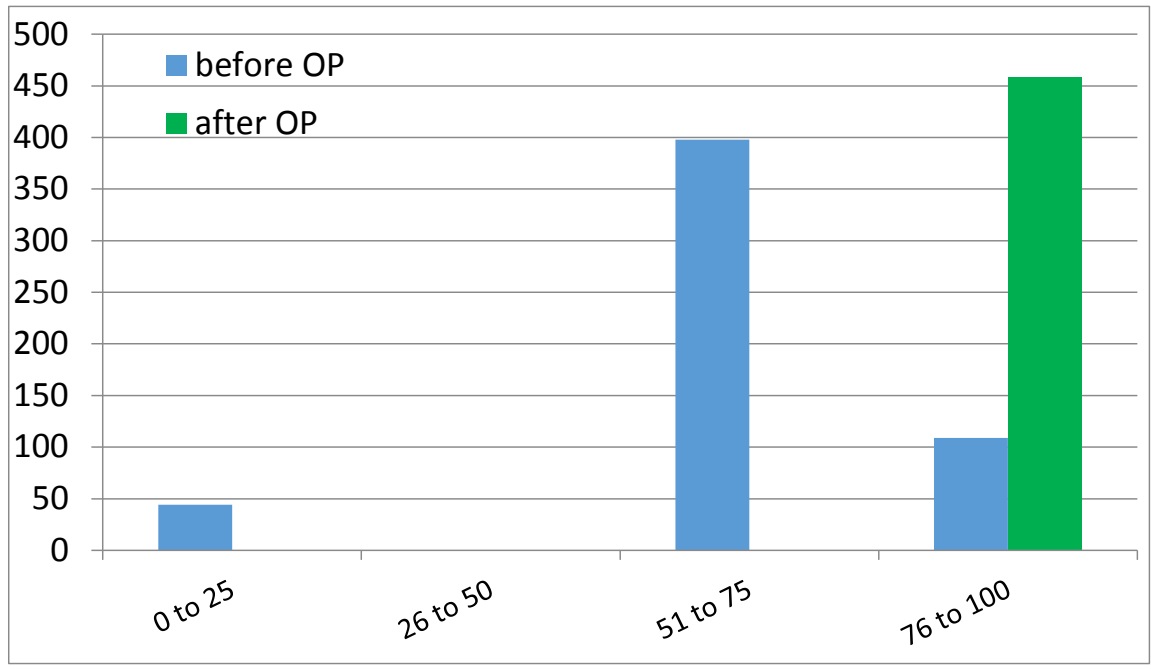

Figure 32. AOFAS before and after OP.

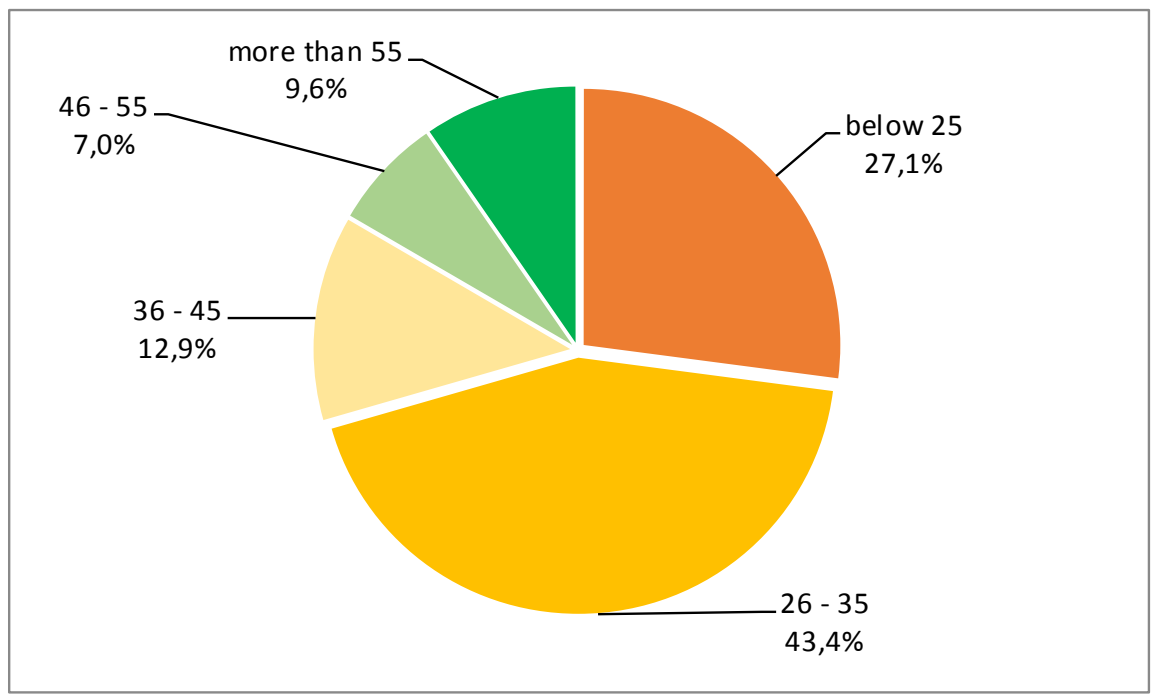

Figure 33. AOFAS-difference before and after OP.

The IM angle improved from mean $12.77^{\circ}$ (from $10^{\circ}$ to $16^{\circ}$ ) to $4.21^{\circ}$ (from $0^{\circ}$ to $\left.8^{\circ}\right)$ which a difference of mean $8.56^{\circ}$ and highly significant $(t=89.70, p<0.001)$ (Table 3. Figure 34, Figure 35).

The Hallux valgus angle (HV) improved also highly significantly $(\mathrm{t}=51.68, \mathrm{p}$ $<0.001$ ) from $32.47^{\circ}$ preoperative (from $16^{\circ}$ to $61^{\circ}$ ) to $7.75^{\circ}$ (from $0^{\circ}$ to $22^{\circ}$ ) which is a difference of mean $24.72^{\circ}$ (Table 4. Figure 36 and Figure 37).

The pronation malrotation decreased from $15.15^{\circ}\left(0^{\circ}-40^{\circ}\right)$ to $1.24^{\circ}\left(0^{\circ}-10^{\circ}\right)$ which is also highly significant $(\mathrm{t}=21.75, \mathrm{p}<0.001)$ (Table 5. Figure 38 and Figure 39).

The DMAA angle decreased from mean $20.84^{\circ}\left(0^{\circ}-40^{\circ}\right)$ to $6.61\left(0^{\circ}-15^{\circ}\right)$ statistically high significant $(\mathrm{t}=29.34 \mathrm{p}<0.001)$ (Table 6. Figure 40 and Figure 41).

The sesamoid position was improved from mean 5.48 (4 - 7) to mean 1.28 (1 3). This is also statistically high significant $(t=65.31, p<0.001)$ (Table 7. Figure 


\section{2, Figure 43).}

The circumference of the forefoot measured in the area of the metatarsal heads was preoperative $24.29 \mathrm{~cm}(21.4 \mathrm{~cm}$ to $26.8 \mathrm{~cm})$ and postoperative 23.24 $\mathrm{cm}(20.2 \mathrm{~cm}$ to $25.2 \mathrm{~cm})$ which is a difference of $1.05 \mathrm{~cm}$ and statistically significant $(\mathrm{t}=37.50, \mathrm{p}<0.001)$ (Table 8. Figure 44 and Figure 45).

The Ist metatarsal head was plantarized mean $2.8 \mathrm{~mm}(0 \mathrm{~mm}-4.2 \mathrm{~mm})$. The shortening of the first metatarsal was $0.33 \mathrm{~mm}$ (between $0 \mathrm{~mm}$ and $2 \mathrm{~mm}$ ).

Table 3. IM angles before and after OP.

\begin{tabular}{ccccccc}
\hline \multicolumn{9}{c}{ Date } \\
\hline before OP $(\mathrm{n}=458)$ & after OP $(\mathrm{n}=458)$ & \multicolumn{2}{c}{ Difference } \\
\hline Variable & mean & s.d. & mean & s.d. & mean & s.d. \\
IM & 12.77 & 1.36 & 4.21 & 1.68 & 8.56 & 2.04 \\
\hline
\end{tabular}

Table 4. HV angles before and after OP.

\begin{tabular}{ccccccc}
\hline \multicolumn{7}{c}{ Date } \\
\hline before OP $(\mathrm{n}=\mathbf{4 5 8 )}$ & after OP $(\mathrm{n}=458)$ & \multicolumn{2}{c}{ Difference } \\
\hline Variable & mean & s.d. & mean & s.d. & mean & s.d. \\
HV & 32.47 & 9.95 & 7.75 & 5.42 & 24.72 & 10.24 \\
\hline
\end{tabular}

Table 5. Pronation before and after OP.

\begin{tabular}{ccccccc}
\hline \multicolumn{7}{c}{ Date } \\
\hline before OP $(\mathrm{n}=458)$ & after OP $(\mathrm{n}=458)$ & \multicolumn{1}{c}{ Difference } \\
\hline Variable & mean & s.d. & mean & s.d. & mean & s.d. \\
Pron & 15.15 & 11.87 & 1.24 & 2.81 & 13.91 & 11.65 \\
\hline
\end{tabular}

Table 6. DMAA before and after OP.

\begin{tabular}{ccccccr}
\hline \multicolumn{7}{c}{ Date } \\
\hline before OP $(\mathrm{n}=458)$ & after OP $(\mathrm{n}=458)$ & \multicolumn{2}{c}{ Difference } \\
\hline Variable & mean & s.d. & mean & s.d. & mean & s.d. \\
DMAA & 20.54 & 8.25 & 6.61 & 5.95 & 13.92 & 8.65 \\
\hline
\end{tabular}

Table 7. Sesamoid-position before and after OP.

\begin{tabular}{ccccccc}
\hline \multicolumn{9}{c}{ Date } \\
\hline before OP $(\mathrm{n}=458)$ & after OP $(\mathrm{n}=458)$ & \multicolumn{2}{c}{ Difference } \\
\hline Variable & mean & s.d. & mean & s.d. & mean & s.d. \\
SESAM & 5.48 & 1.15 & 1.28 & 0.50 & 4.20 & 1.17 \\
\hline
\end{tabular}




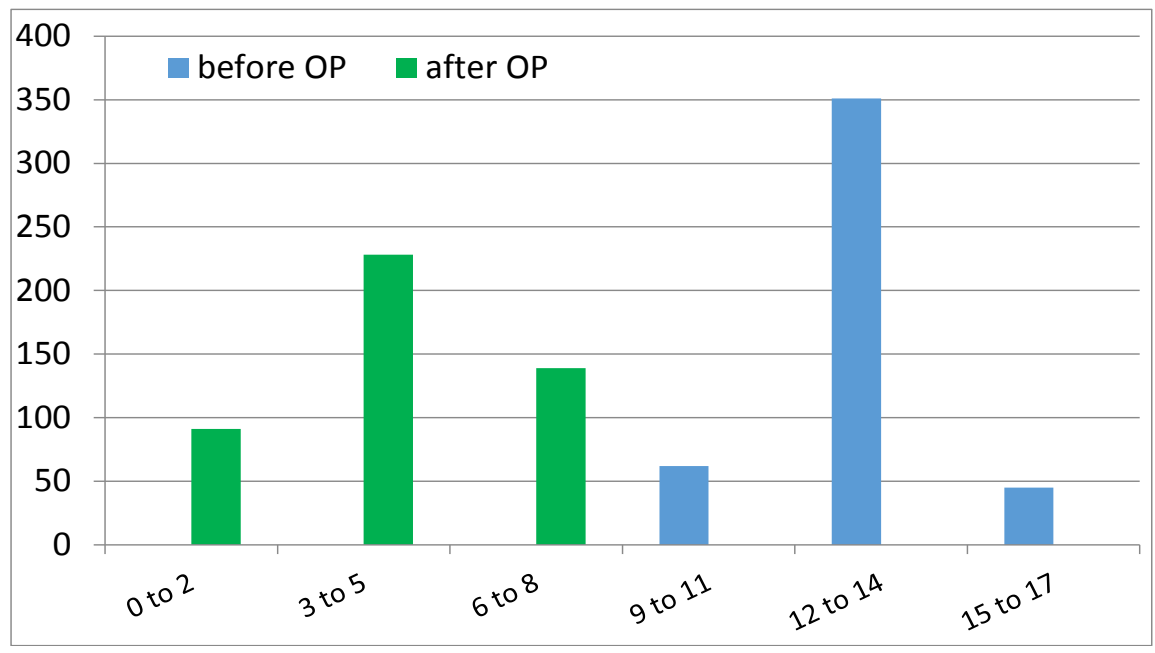

Figure 34. IM angles before and after OP.

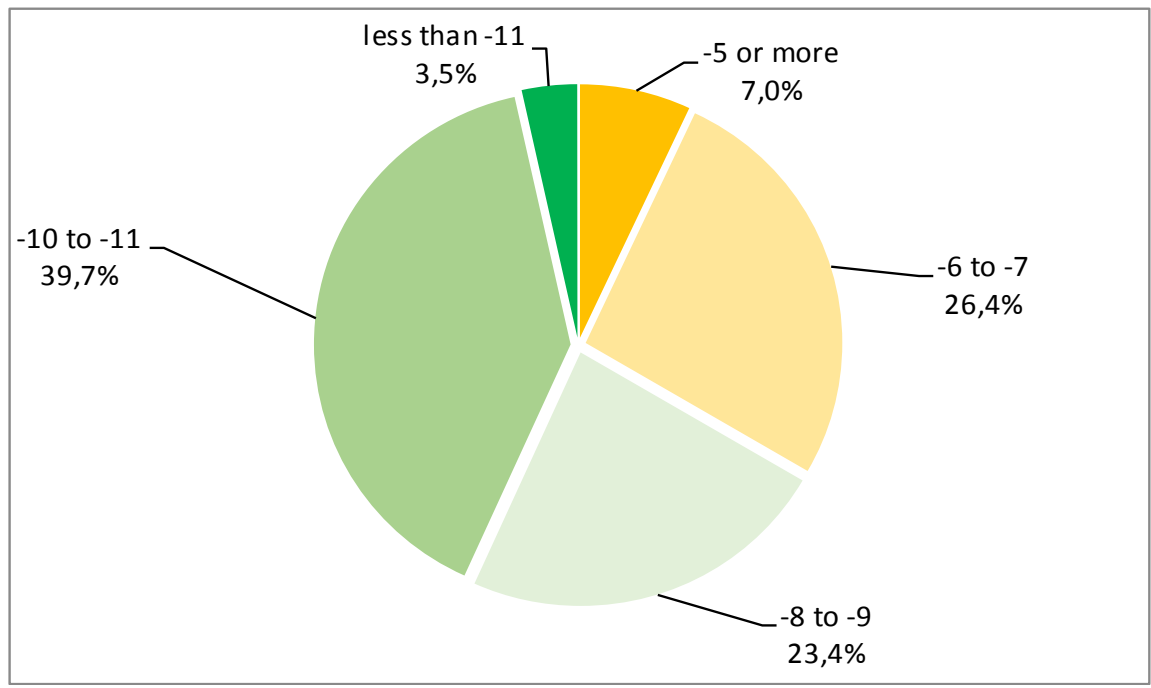

Figure 35. IM angle-difference before and after OP.

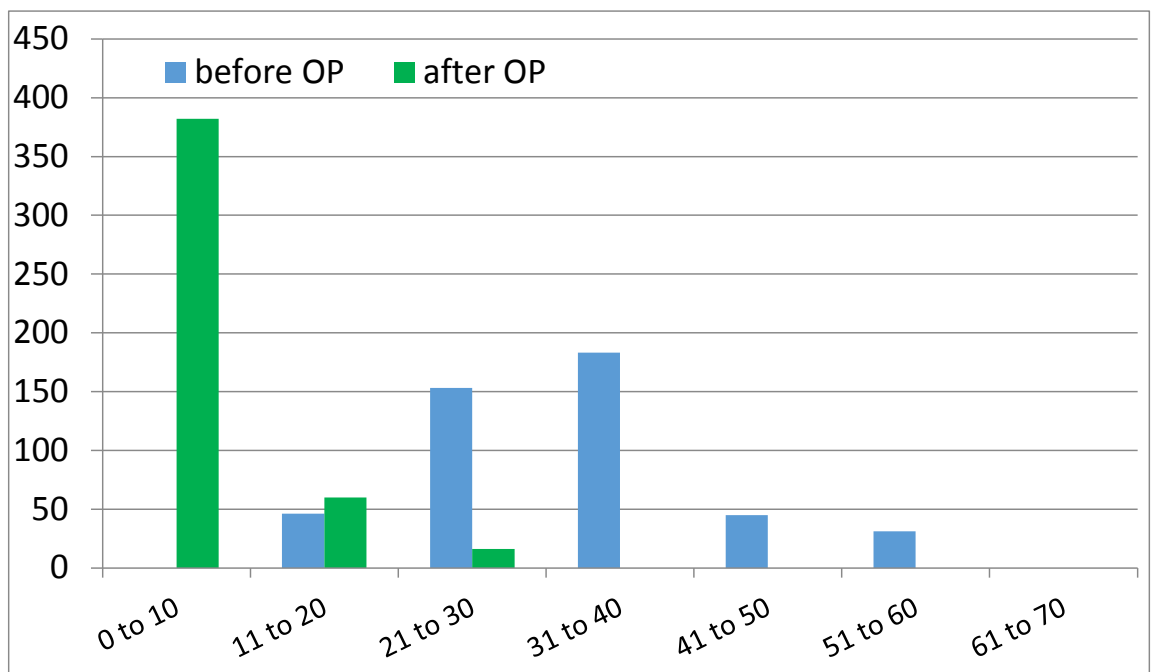

Figure 36. HV angles before and after OP. 
Table 8. Circumferences before and after OP.

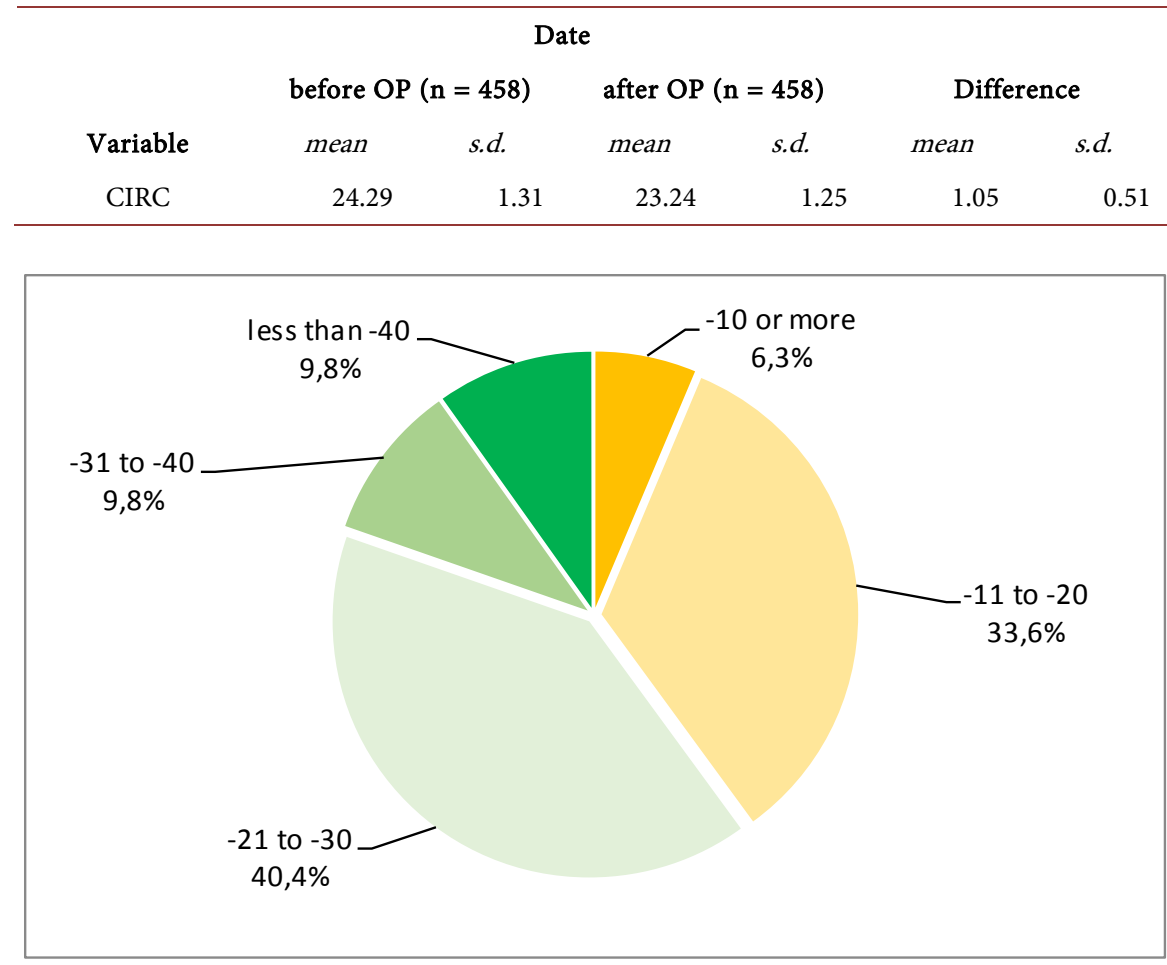

Figure 37. HV angle-difference before and after OP.

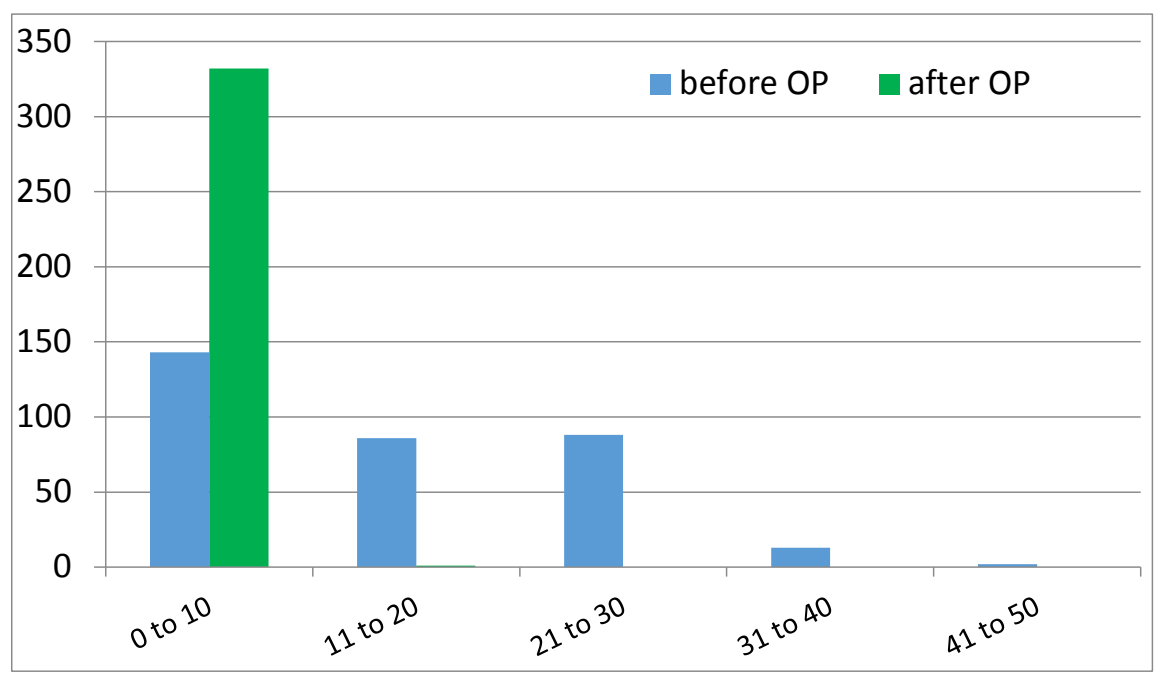

Figure 38. Pronation before and after OP.

94.6\% of the patients were very satisfied or satisfied with the operation. 3.8\% rated the operation as fair and $1.6 \%$ were unsatisfied. Except of the removal of osteosynthesis in material $8 \%$ no reoperations were necessary.

\section{Complications}

We recorded 3 cases $(0.69 \%)$ of transfer metatarsalgia.

Other complications were swellings in $82 \%$, delayed wound healing in 5 cases 
with help of antibiotics (1.15\%), and four broken screws because we used only one distal screw initially. The outcome of the operation was not impaired by the screw breakage. These are the cases with shortenings of $2 \mathrm{~mm}$. After changing the design of the plate to 2 screws, the problem was resolved. There were no cases of malunion, no deep infection. We had to remove the osteosynthesis material (one screw or all screws and the plate) in 35 cases (8\%) due to loosenings of screws or impingement of soft tissue.

\section{Discussion}

The subcapital osteotomy performed with a lazy-L permits to correct all particular occurring deformities in the entity of the mild to moderate hallux valgus. We did not focus to achieve a good bone contact between the osteotomy partners and we did not aim to get a bone compression to avoid shortening. As

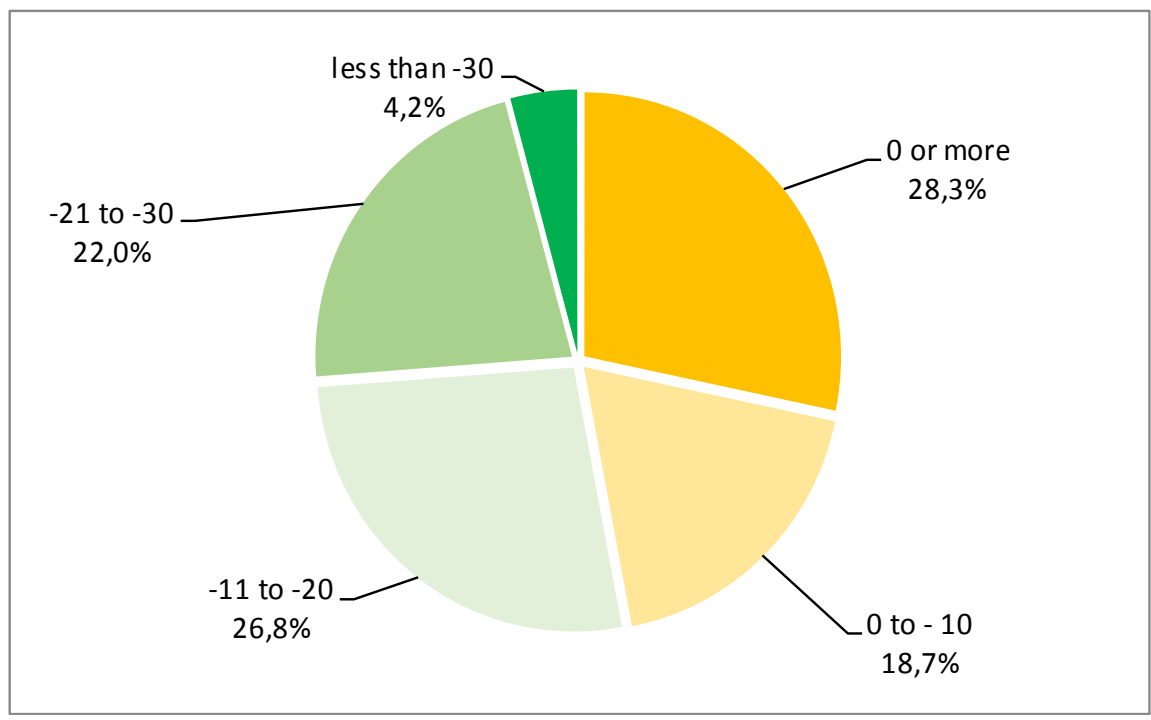

Figure 39. Pronation-difference before and after OP.

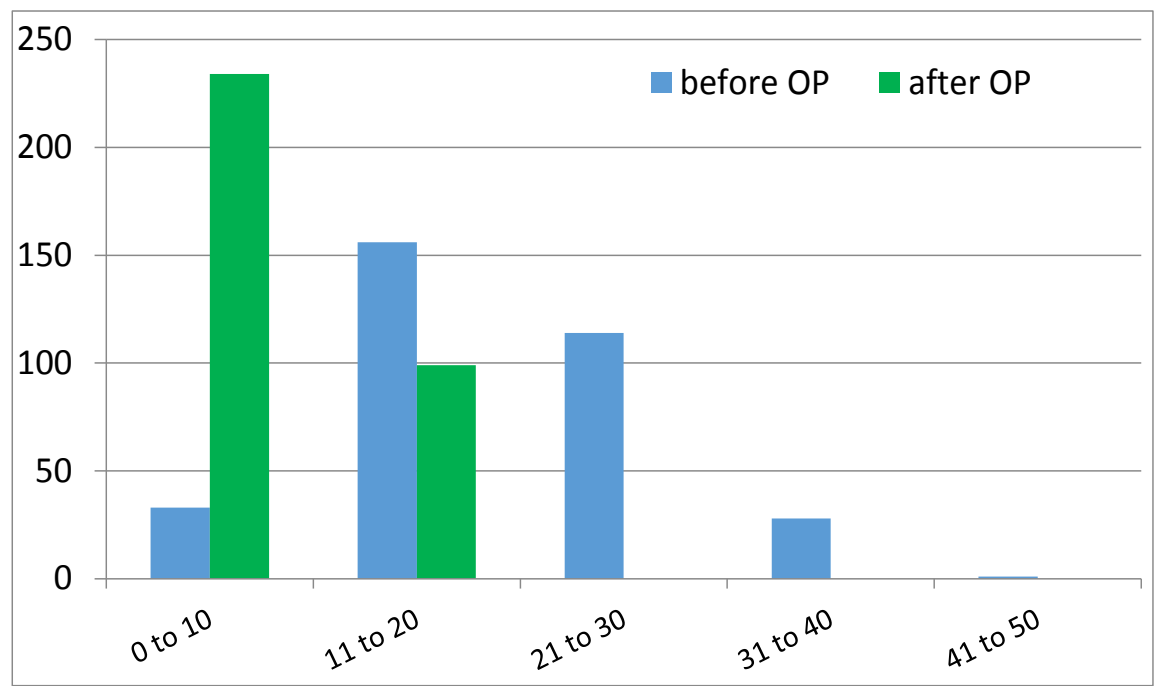

Figure 40. DMAA before and after OP. 


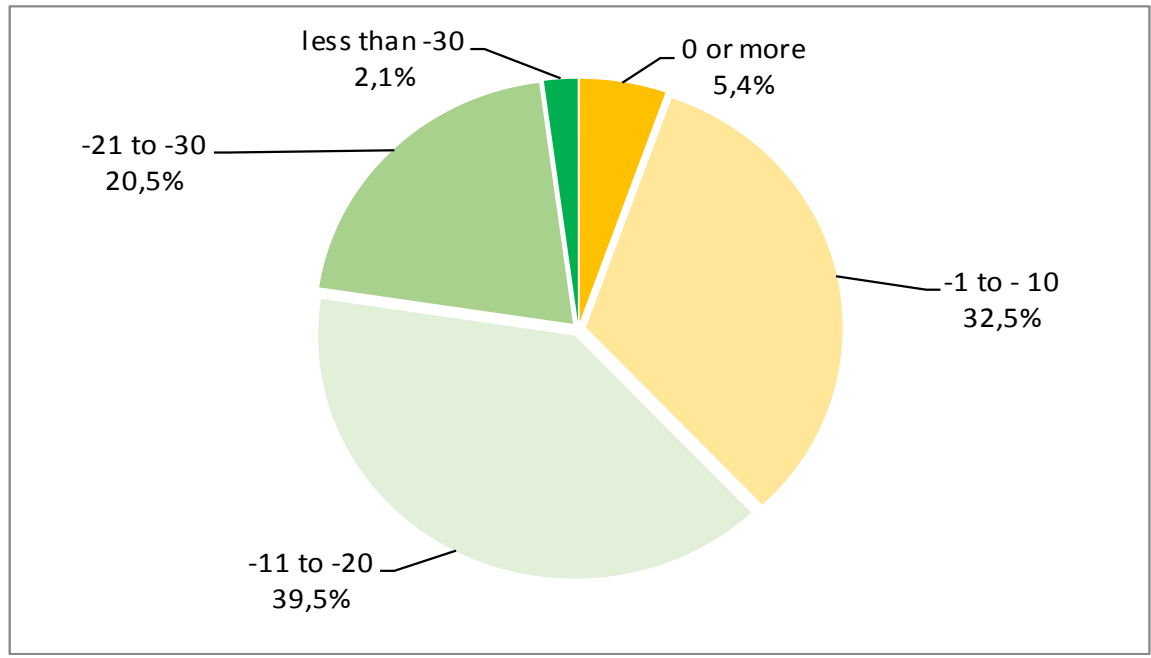

Figure 41. DMAA—-difference before and after OP.

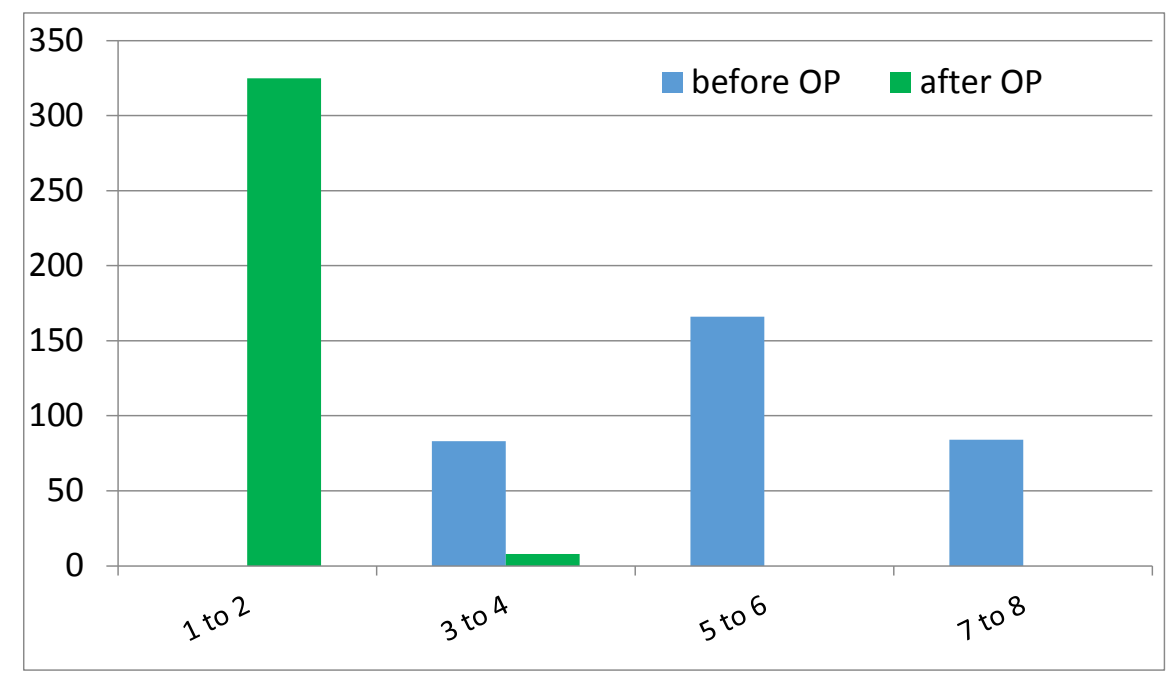

Figure 42. Sesamoid-position before and after OP.

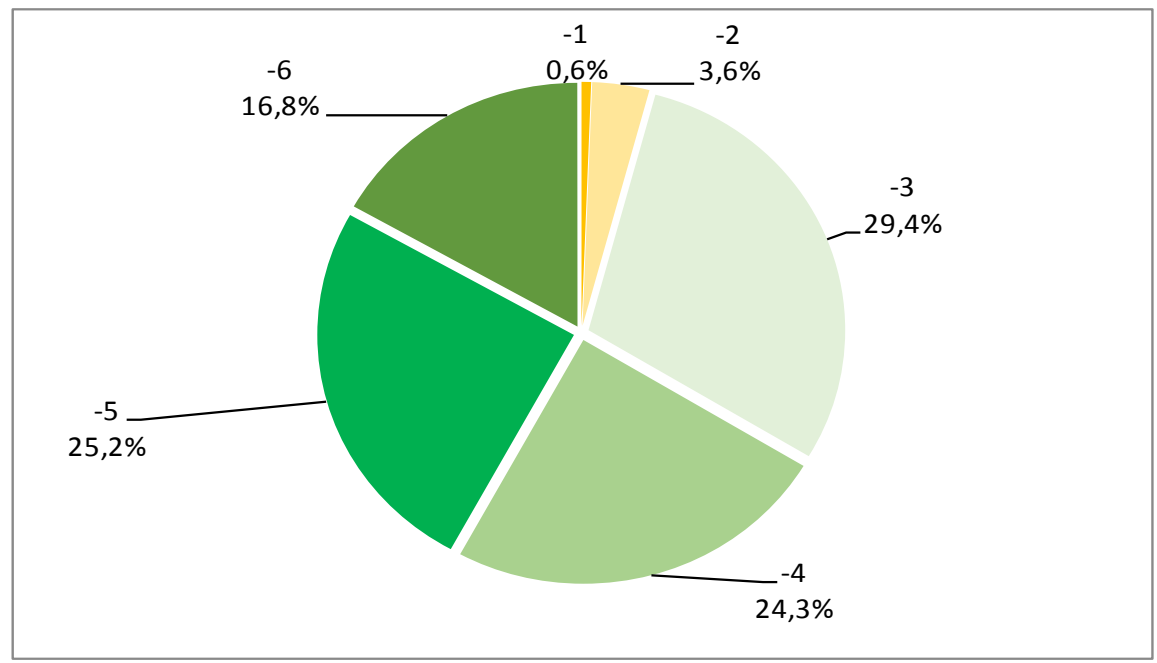

Figure 43. Sesamoid-position difference before and after OP. 


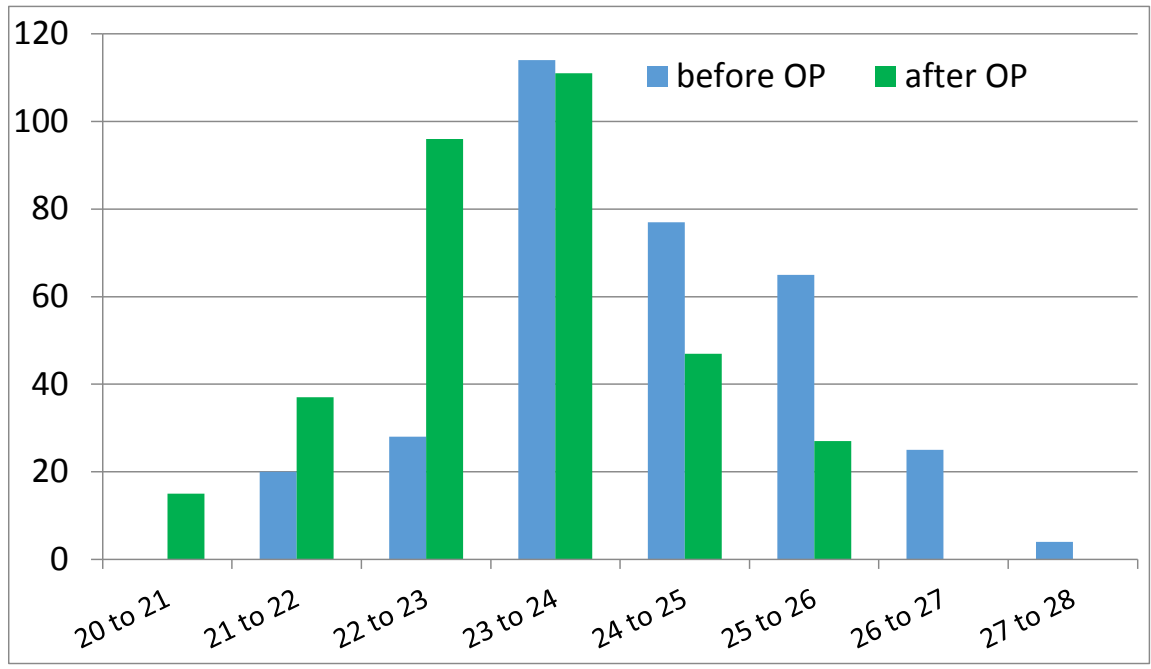

Figure 44. Circumferences before and after OP.

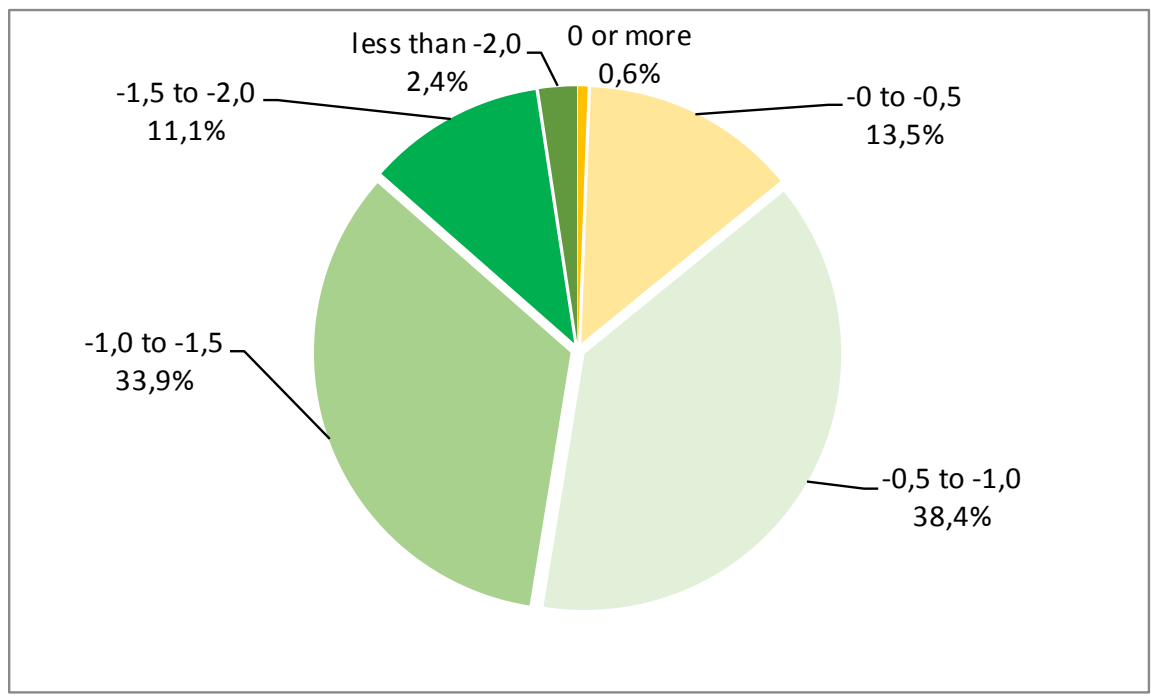

Figure 45. Circumference-difference before and after OP.

proven in the study, point contact between the osteotomized bone partners is sufficient. The osteosynthesis plates-which were developed in cooperation with a medical company in 2006-are intramedullary angle stable fixed in the proximal aspect. The distal osteotomized bone partner is fixed in an angle-stable manner to the distal part of the plate. These implants were very rigid, and patients were mobilized immediately with full weighbearing. In X-rays we did not notice any changing in the position until bone healing occurred, which usually took eight weeks.

The results of the study show, that there could be highly significant corrected or improved all types of deformities in terms of IM angle, HV angle, DMAA, Sesamoid position, pronation malrotation, circumference of the foot, elevation of the Ist metatarsal head avoiding shortenings or immobilization of the Ist MPJ. The majority of the patients (94.6\%) was very satisfied and satisfied with the op- 
eration.

\section{Ethical Clearance}

The authors declare no conflict of interests. The informed consent was obtained from all patients before the operation.

\section{References}

[1] Richter, M. (2010) Revised Guidelines for Foot and Ankle Surgery. Aktualisierte Leitlinien Fuß und Sprunggelenk. Fuss Sprung, 8, 268-287.

https://doi.org/10.1016/j.fuspru.2010.08.003

[2] Wuilker, N. (1997) Hallux Valgus-Hallux Rigidus. Enke-Verlag, Stuttgart.

[3] Boebel, A. and Wolff, K. (1960) Relation between Lenght of Metatarsal I and Hallux Valgus. Uber die Beziehung zwischen Großzehenlänge und Hallux Valgus. Zeitschrift für Orthopädie und Unfallchirurgie, 93, 254-259.

[4] Donick, I.I., Berlin, S.J., Block, L.D., Costa, A.J., Fox, J.S. and Martorana, V.J. (1980) An approach for Hallux Valgus. Journal of Foot Surgery, 19, 113.

[5] Kilmartin, T.E., Barrington, R.L. and Wallace, W.A. (1991) Metatarsus Primus Varus, a Statistical Study. The Journal of Bone and Joint Surgery, 373-B, 937-940.

[6] Coughlin, M.J. and Jones, C.P. (2007) Hallux Valgus: Demographics, Etiology, and Radiographic Assessment. Foot \& Ankle International, 28, 759-777. https://doi.org/10.3113/FAI.2007.0759

[7] Coughlin, M.J., Saltzman, C.L. and Nunley, J.A. (2002) Angular Measurements in the Evaluation of Hallux Valgus Deformities: A Report of the Ad Hoc Committee of the American Orthopaedic Foot \& Ankle Society on Angular Measurements. Foot \& Ankle International, 23, 68-74. https://doi.org/10.1177/107110070202300114

[8] Wülker, N. and Mittag, F. (2012) The Treatment of Hallux Valgus, Deutsches Arrteblatt International, 109, 857-868.

[9] Austin, D.W. and Leventen, E.O. (1981) A New Osteotomy for Hallux Valgus: A Horizontally Directed "V" Displacement Osteotomy of the Metatarsal Head for Hallux Valgus and Primus Varus. Clinical Orthopaedics and Related Research, No. 157, 25-30. https://doi.org/10.1097/00003086-198106000-00007

[10] Havlícek, V., Kovanda, M. and Kunovsky, R. (2007) Surgical Management of Hallux Valgus by Techniques Preserving the First Metatarsophalangeal Joint: Long-Term Results. Acta chirurgiae orthopaedicae et traumatologiae Cechoslovaca, 74, 105-110.

[11] Steinböck, G. (1996) Austin's Horizontal V-Shaped Sliding Osteotomy of the Metatarsal Head Chevron-Osteotomy) in the Treatment of Hallux Valgus. Orthopade, 25, 308-316.

[12] Trnka, H.J., Zembsch, A., Wiesauer, H., Hungerford, M., Salzer, M. and Ritschl, P. (1997) Modified Austin Procedure for Correction of Hallux Valgus. Foot \& Ankle International, 18, 119-127. https://doi.org/10.1177/107110079701800302

[13] Othman, A. and Hegazy, I. (2016) Treatment of Mild to Moderate Hallux Valgus, Percutaneous Osteotomy versus Distal Chevron Osteotomy. Open Journal of Orthopedics, 6, 150-157. https://doi.org/10.4236/ojo.2016.66023

[14] Youngswick, F.D. (1982) Modifications of the Austin Bunionectomy for Treatment of Metatarsus Primus Elevatus Associated with Hallux Limitus. Journal of Foot and Ankle Surgery, 21, 114-116.

[15] Ahn, J., Lee, H.S., Seo, J.H. and Kim, J.Y. (2016) Second Metatarsal Transfer Lesions 
Due to First Metatarsal Shortening After Distal Chevron Metatarsal Osteotomy for Hallux Valgus. Journal of Foot and Ankle Surgery, 37, 589-595. https://doi.org/10.1177/1071100715627350

[16] Richard, V.D., Jeffrey, H., Michael, W., Heaslet, M.S. and Walston, S. (2003) Complications of Screw-Fixated Chevron Osteotomies for the Correction of Hallux Abducto Valgus. Journal of the American Podiatric Medical Association, 93, 499-502. https://doi.org/10.7547/87507315-93-6-499

[17] Lagaay, P.M., Hamilton, G.A., Ford, L.A., Williams, M.E., Rush, S.M. and Schuberth, J.M. (2008) Rates of Revision Surgery Using Chevron-Austin Osteotomy, Lapidus Arthrodesis, and Closing Base Wedge Osteotomy for Correction of Hallux Valgus Deformity. Journal of Foot and Ankle Surgery, 47, 267-272. https://doi.org/10.1053/j.jfas.2008.03.002

[18] Duan, X.J. and Kadakia, A.R. (2012) Salvage of Recurrence after Failed Surgical Treatment of Hallux Valgus. Article in Archives of Orthopaedic and Trauma Surgery, 132, 477-485. https://doi.org/10.1007/s00402-011-1447-6

[19] Reverdin, J. (1881) The Deviation of Hallux Valgus and Its Treatment. De la deviation en dehors du gros orl (hallux valgus) et son traitement chirurgical. Trans International Medical Congress, 2, 408-412.

[20] Hohmann, G. (1924) About the Hallux Valgus Operation. Zur Hallux Valgus-Operation. Zentralblatt Chirurgie, 51, 230.

[21] Hohmann, G. (1925) Hallux Valgus and Deformities of the Lesser Toes. Der Hallux valgus und die übrigen Zehenverkrümmungen. Ergebnisse der Chirurgie und Orthopädie, 18, 308.

[22] Christensen, P.H. and Hansen, T.B. (1995) Hallux Valgus Correction Using a Modified Hohmann Technique. Foot \& Ankle International, 16, 177-180. https://doi.org/10.1177/107110079501600401

[23] Vanore, J.V. (1994) Hohmann Osteotomy, Chapter 13 in Hallux Valgus and Forefoot Surgery. In: Vincent, J., Ed., Hetherington, Churchill Livingstone, New York, 183-196.

[24] Trnka, H.J., Krenn, S. and Schuh, R. (2013) Minimally Invasive Hallux Valgus Surgery: A Critical Review of the Evidence. International Orthopaedics, 37, 1731-1735. https://doi.org/10.1007/s00264-013-2077-0

[25] Roukis, T.S. (2009) Percutaneous and Minimum Incision Metatarsal Osteotomies: A Systematic Review. The Journal of Foot and Ankle Surgery, 48, 380-387. https://doi.org/10.1053/j.jfas.2009.01.007

[26] Díaz Fernández, R. (2017) Percutaneous Triple and Double Osteotomies for the Treatment of Hallux Valgus. Foot \& Ankle International, 38, 159-166. https://doi.org/10.1177/1071100716670403

[27] Magin, M.N. (2011) Stoffella Metatarsal I Osteotomy for Hallux Valgus Correction: An Update. Operative Orthopadie und Traumatologie, 23, 158-166. https://doi.org/10.1007/s00064-010-0013-7

[28] Wolter, L. (2004) Hueter Mayo Resectionarthroplasty in Hallux Valgus versus Stoffella Subcapital I-Osteteotomy. Resektionsinterpositionsarthropastik nach Hueter Mayo bei Hallux valgus versus subcapitale Metatarsale-I-Osteotomie nach Stoffella bei Hallux valgus. Dissertation Ruhr Universität Bochum 2004.

[29] Kramer, J. (1990) The Kramer Osteotomy in the Correction of Hallux Valgus and Digitus Quintus Varus. Die Kramer-Osteotomie zur Behandlung des Hallux valgus und des Digitus quintus varus. Operative Orthopädie und Traumatologie, 2, 29-38. 
https://doi.org/10.1007/BF02512334

[30] Lamprecht, E. (1993) Kramers Retrocapital Metatarsal I Osteotomy. Retrokapitale Metatarsale-I-Osteotomie nach Kramer. In: Wirth, C.J., Ferdini, R. and Wuilker, N., Eds., Vorfußdeformitäten, Springer, Berlin, 241-250.

[31] Bösch, P., Markowski, H. and Rannicher, V. (1990) Technique and First Results of t he Subcutaneous Distal Ostetomy of Metatarsal I. Technik und erste Ergebnisse der subcutanen distalen Metatarsale-I-Osteotomie. Orthopädische Praxis, 26, 51-56.

[32] Bösch, P., Wanke, S. and Legenstein, R. (2000) Hallux Valgus Correction by the Method of Bösch: A New Technique with a Seven to Ten Year Follow-Up. Foot and Ankle Clinics, 5, 485-498.

[33] Iannò, B., Familiari, F., De Gori, M., Galasso, O., Ranuccio, F. and Gasparini, G. (2013) Midterm Results and Complications after Minimally Invasive Distal Metatarsal Osteotomy for Treatment of Hallux Valgus. Foot \& Ankle International, 34, 969-977. https://doi.org/10.1177/1071100713481453

[34] Burutaran, J.M. (1976) Hallux valgus y cortedad anatomica del primer metatarsano (correction quingica). Actual Medicina e Chirurgia del Piede, 13, 261-266.

[35] Fakoor, M., Sarafan, N., Mohammadhoseini, P., Khorami, M., Arti, H., Mosavi, S., and Aghaeeaghdam, A. (2014) Comparison of Clinical Outcomes of Scarf and Chevron Osteotomies and the McBride Procedure in the Treatment of Hallux Valgus Deformity. The Archives of Bone and Joint Surgery, 2, 31-36.

[36] Crevoisier, X., Mouhsine, E., Ortolano, V., Udin, B. and Dutoit, M. (2001) The Scarf Osteotomy for the Treatment of Hallux Valgus Deformity: A Review of 84 Cases. Foot \& Ankle International, 22, 970-976. https://doi.org/10.1177/107110070102201208

[37] Coetzee, J.C. (2003) Scarf Osteotomy for Hallux Valgus Repair: The Dark Side. Foot \& Ankle International, 24, 29-33. https://doi.org/10.1177/107110070302400104

[38] Chandler, L.M. (2014) First Metatarsal Head Osteotomies for the Correction of Hallux Abducto Valgus. Clinics in Podiatric Medicine and Surgery, 31, 221-231. https://doi.org/10.1016/j.cpm.2013.12.004

[39] Lehman, D.E. (2003) Salvage of Complications of Halluxvalgus Surgery. Foot and Ankle Clinics, 8, 15-35. https://doi.org/10.1016/S1083-7515(02)00130-4

[40] Duan, X.J. and Kadakia, A.R. (2011) Salvage of Recurrence after Failed Surgical Treatment of Hallux Valgus. Article in Archives of Orthopaedic and Trauma Surgery, 132, 477-485. https://doi.org/10.1007/s00402-011-1447-6

[41] Vitek, M. (2009) New Techniques in Forfoot Surgery. The V-Tek System. K-Wire Free Forefoot Corrections. Neue Techniken in der Fußchirurgie-das V-tek-System: Bohrdrahtfreie Vorfußkorrekturen. ABW Wissenschaftsverlag.

[42] Akin, O. (1925) The Treatment of Hallux Valgus: A New Operative Procedure and Its Results. Medical Sentinel, 33, 678-679. 
Submit or recommend next manuscript to SCIRP and we will provide best service for you:

Accepting pre-submission inquiries through Email, Facebook, LinkedIn, Twitter, etc. A wide selection of journals (inclusive of 9 subjects, more than 200 journals)

Providing 24-hour high-quality service

User-friendly online submission system

Fair and swift peer-review system

Efficient typesetting and proofreading procedure

Display of the result of downloads and visits, as well as the number of cited articles Maximum dissemination of your research work

Submit your manuscript at: http://papersubmission.scirp.org/

Or contact ojo@scirp.org 